Sharif University of Technology
Scientia Iranica
SCIENTIA
IRAN ICAA

\title{
Effects of viscoelastic supports on the behavior of bridges under moving vehicles
}

\author{
K. Samanipour* and H. Vafai \\ Department of Civil Engineering, Sharif University of Technology, Tehran, Iran.
}

Received 15 June 2015; received in revised form 4 April 2016; accepted 10 May 2016

\section{KEYWORDS}

Bridge;

Dynamics;

Viscoelastic supports;

Maximum dynamic

stress;

Stress analysis;

Finite difference

method.

\begin{abstract}
One of the most important problems facing structural engineers is the analysis of dynamic behavior of bridges subjected to moving vehicles. In addition, viscoelastic supports under bridges change their dynamic behavior under passing traffic loads. This paper presents how to model a bridge with viscoelastic supports and how the maximum dynamic stress of bridges changes during the passing of moving vehicles. Furthermore, this paper presents an algorithm to solve the governing equation of the bridge with viscoelastic supports as well as the equation of motion of a real European truck with different speeds, simultaneously. Using viscoelastic supports with appropriate characteristics can make a significant difference in the magnitude on the maximum dynamic stress of bridges. By finite difference method, it will be shown that how much the stiffness and damping of viscoelastic supports should be to have less impact and dynamic stresses in the bridges. It will be demonstrated that using viscoelastic supports can decrease the local maximum DAFs in the case of short and medium spans up to $5 \%$. This study becomes more important where vehicle speeds are considerably high; therefore, the consequences of a full-length analysis with viscoelastic supports must be used to design safe bridges.

(C) 2017 Sharif University of Technology. All rights reserved.
\end{abstract}

\section{Introduction}

Dynamic behavior of bridges subjected to moving forces (moving loads, moving masses, and moving vehicles) is one of the most important problems facing design and structural bridge engineers. In addition, the approaches to analysis of the bridges under moving forces have the same importance and these approaches are being developed by design bridge engineers by considering more factors influencing dynamic behavior of the bridge. The forces that vary in both time and space are called moving forces based on general mechanics parlance. For instance, transport engineering structures are subject to such forces. In recent years,

\footnotetext{
* Corresponding author. Tel.: +982188900064 Fax: +982186035250

E-mail address: Kianoosh_samanipour@yahoo.com (K. Samanipour)
}

increasingly higher speeds and weights of vehicles have had a great influence in all branches of transport. As a result, vibrations and dynamic stresses far larger than ever before occur in structures and media over or in which the vehicles move.

Jeffcott in 1929, Steuding in 1943, and Odman in 1951 first studied the influence of a moving mass on the dynamic response of a structure [1]. Many approximations were involved in their solution, which made it impractical. Fryba [2] wrote a helpful book containing almost all of the previous work in the field of vibration of solids and structure under moving loads.

Zheng et al. [3] studied the vibration of vehicles on compressed rails on a viscoelastic foundation. They utilized a theoretical and analytical approach to solve the problem considering resonance parameters as well. Other papers have been written considering acceleration of moving mass, friction between moving 
mass and bridge [4], cantilever beams [5], large free vibrations [6], and curved beams [7]. Dehestani et al. [8] investigated critical influential speed for moving mass problems on the beams with different end conditions. In other research, Mofid et al. [9] presented two methods to determine the dynamic behavior of viscoelastic beams subjected to moving mass. Cantero et al. [10] calculated the maximum dynamic stress on simply supported bridges traversed by moving vehicles.

Bridge codes take different approaches to considering dynamic effects due to moving traffic. For example, the American Association of State Highway and Transportation Officials [11] defines a factor called DLA (Dynamic Load Allowance), which considers the dynamic effects of moving vehicles and applies them to the maximum static stresses. For fatigue and fracture the AASHTO proposes the DLA to be 1.15 and 1.33 for all other limit states for all spans [12]. In the Eurocode EN 1991-2 [13], different load models based on experimental results from a number of countries are defined. For each load model, different dynamic factors obtained from numerical simulations are used. Dynamic effects are combined with static results to obtain characteristic values by using these dynamic factors.

During 2011 to 2014, many studies, particularly considering the moving oscillator effects on the bridge behavior, were done in different universities and research institutions [14-16]. The authors investigated the effect of boundary conditions on dynamic behavior of bridges under actual European moving trucks [17], as well as the congestion effect on maximum dynamic stresses of bridge under two actual moving trucks [18].

In summary, because of the importance of the safety of bridges, many research works and simulations are being carried out to predict the dynamic amplification factors by different universities and institutions all over the world. But, viscoelastic supports and their influences have not been investigated well in previous studies and, usually, the researchers assume that the bridges are simply supported. Furthermore, analyzing the influence of viscoelastic support with respect to variations of truck speed, bridge spans, and road profiles and its effect on the variations of the dynamic amplification factors has many significances as well. In this paper, the problem definition is supplied and afterwards an algorithm to solve the governing equation of actual European truck moving on different bridges considering viscoelastic supports is presented. The present work extends the scope of previous studies by considering actual truck moving instead of moving mass problem, [8,9], and by considering viscoelastic supports for the beam loading, $[10,17,18]$. The critical velocities considering viscoelastic supports to get maximum dynamic stresses of the beam are numerically calculated.
In this paper, the following assumptions are made. First, dynamic characteristics of the beam are described by Euler-Bernoulli beam equation. Furthermore, the beam is assumed to be of constant crosssection with uniform mass distribution and is hinged at both ends on viscoelastic supports. Second, the effects of inertia for both the beam and the moving truck are taken into account with the gravitational effect of load. Third, the truck move with constant speed is guided in such a way that the probable uplifts of tires are considered in the analyses. The objectives of this investigation are: (1) To formulate the solution of the problem in the general form; (2) To present a practical and precise technique for determining the dynamic response of a Euler-Bernoulli beam, considering viscoelastic supports; (3) To verify the model with previous studies; (4) To study the important factors such as moving truck velocity, viscoelastic supports, and beam length in the dynamic amplification factors, which cause more or less dynamic stresses in bridges.

\section{Problem definition}

For an Euler-Bernoulli beam under static load case, the governing equation is:

$$
E I \frac{\partial^{4} y}{\partial x^{4}}=P(x) .
$$

Figure 1 shows an Euler-Bernoulli beam carrying an oscillating load $\mathrm{P}(x, t)$, which can vary with time and location.

The equation of motion of the Euler-Bernoulli beam can be expressed [2] in the form:

$$
E I \frac{\partial^{4} y}{\partial x^{4}}+2 \mu \omega_{b} \frac{\partial y}{\partial t}+\mu \frac{\partial^{2} y}{\partial t^{2}}=P(x, t)
$$

where $y(x, t)$ is the vertical deflection of the beam at location $x$ and instant $t$; $I$ is the second moment of area; $E$ is the modulus of elasticity; $\omega_{b}$ is the damped circular frequency; and $\mu$ is the constant mass per unit length of the beam.

Figure 2 shows a moving object which is travelling at a constant horizontal velocity $C$ along the beam.

The equation of motion of the Euler-Bernoulli beam for moving load case can be expressed [2] in the

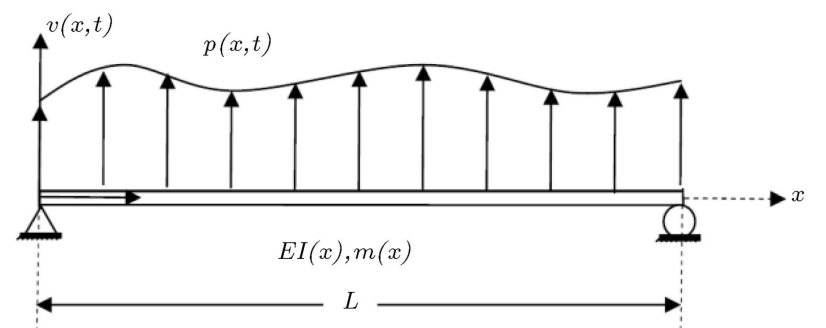

Figure 1. Beam general model. 


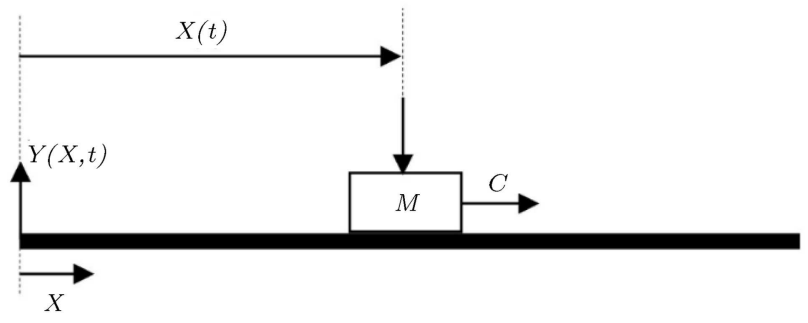

Figure 2. Beam carrying moving load.

form:

$$
E I \frac{\partial^{4} y}{\partial x^{4}}+2 \mu \omega_{b} \frac{\partial y}{\partial t}+\mu \frac{\partial^{2} y}{\partial t^{2}}=-M g \times \delta(x-X)
$$

where $\delta$ is the Dirac function.

If the mass of the moving objects has been taken into account in writing the governing equation, the problem is in the form [2]:

$$
E I \frac{\partial^{4} y}{\partial x^{4}}+2 \mu \omega_{b} \frac{\partial y}{\partial t}+\mu \frac{\partial^{2} y}{\partial t^{2}}=-M\left[\frac{\partial^{2} y}{\partial t^{2}}+g\right] \delta(x-X) \text {. }
$$

The term $\frac{\partial^{2} y}{\partial t^{2}}$ represents vertical acceleration of the moving object. Eq.(4) is valid if the moving mass has low speed. If the moving mass has high speed, Eq. (5) considering full acceleration term (i.e. $\frac{d^{2} y}{d t^{2}}=$ $\left.\frac{\partial^{2} y}{\partial t^{2}}+c^{2} \frac{\partial^{2} y}{\partial x^{2}}+2 c \frac{\partial^{2} y}{\partial t \partial x}\right)$ must be used.

$$
\begin{aligned}
E I \frac{\partial^{4} y}{\partial x^{4}}+2 \mu \omega_{b} \frac{\partial y}{\partial t}+\mu \frac{\partial^{2} y}{\partial t^{2}}= \\
-M[\underbrace{c^{2} \frac{\partial^{2} y}{\partial x^{2}}+2 c \frac{\partial^{2} y}{\partial t \partial x}+\frac{\partial^{2} y}{\partial t^{2}}}_{\frac{d^{2} y}{d t^{2}}}+g] \partial(x-X),
\end{aligned}
$$

where $c$ is the vehicle speed [2].

If there are some springs and dampers between the moving object and the beam surface, the problem becomes more complicated. The equations of motion for this kind of system, which is called a moving oscillator, can be expressed in the following form [10]:

$$
\begin{aligned}
& E I \frac{\partial^{4} y}{\partial x^{4}}+2 \mu \omega_{b} \frac{\partial y}{\partial t}+\mu \frac{\partial^{2} y}{\partial t^{2}}=\sum_{i=1}^{n} \delta\left(x_{i}-c t\right) F_{t i}(t), \\
& \mathbf{M} \ddot{\mathbf{u}}+\mathbf{C} \dot{\mathbf{u}}+\mathbf{K u}=\mathbf{F},
\end{aligned}
$$

where $\mathbf{M}$ is the mass matrix; $\mathbf{C}$ is the damping matrix; $\mathbf{K}$ is the stiffness matrix of the suspension system; $\mathbf{u}$ is the vector of DOF's displacement of the system; and $\mathbf{F}$ is the force vector between the moving object and the beam surface and is a function of both $y(x, t)$ and $\mathbf{u}$. The dimension of mass, damping, and stiffness matrices is same as the number of DOF of the system. The main difficulty in this problem is that Eqs. (6) and (7) are coupled and must be solved simultaneously.

\section{Bridge model}

As mentioned before, the governing equation of the Euler-Bernoulli beam under moving vehicle with the length $L$, second moment of area $I$, modulus of elasticity $E$, and constant mass per unit length $\mu$ can be written as in Eq. (6); where $y(x, t)$ is the vertical displacement of the beam due to the force $F(x, t)$ at section $x$ and time $t$.

$\omega_{b}$ is the damped circular frequency and for small damping ratios, $\xi$, is given [10] by:

$$
\begin{aligned}
\omega_{b} & =\frac{\xi}{\sqrt{1-\xi^{2}}} \omega_{j} \approx \xi \omega_{j}, \\
\omega_{j}^{2} & =\frac{j^{4} \pi^{4}}{L^{4}} \frac{E I}{\mu} \\
\omega_{j} & =j^{2} \omega_{1},
\end{aligned}
$$

where $\omega_{j}$ are natural frequencies of the bridge.

As a result, for a system with a moving truck with $n$ axles, the governing equation can be written as:

$$
\begin{gathered}
E I \frac{\partial^{4} y(x, t)}{\partial x^{4}}+\mu \frac{\partial^{2} y(x, t)}{\partial t^{2}}+2 \mu \omega_{b} \frac{\partial y(x, t)}{\partial t}= \\
\left.\sum_{i=1}^{n} \delta\left(x_{i}-c_{1} t\right) F_{t i}(t)\right|_{\text {vehicle }} .
\end{gathered}
$$

For a beam carrying a moving vehicle, the equation of motion of the vehicle model, Eq. (7), is used, where $\mathbf{M}$ is mass; $\mathbf{C}$ is damping, and $\mathbf{K}$ is stiffness matrices of the vehicle model. $\mathbf{u}$ and $\mathbf{F}$ are vectors of generalized coordinates and forces for vehicle model.

The vehicle tires are prevented from uplift (negative force) by the following condition:

$$
\begin{gathered}
F_{i}=K_{\text {tire }, i}\left(y_{\text {veh. }, i}-y_{\text {bridge }, i}+r_{i}\right) \geq 0, \\
i=1,2, \ldots, n,
\end{gathered}
$$

where $n$ is the number of vehicle axles; $y_{\text {bridge, } i}$ is the displacement of the beam; and $r_{i}$ is the road profile underneath the $i$ th axle of vehicle at instant t. The coupled Eqs. (7), (11), and (12) must be solved simultaneously.

\section{Modeling of viscoelastic end condition}

Figure 3 shows an Euler-Bernoulli beam, carrying an oscillating load, $P(x, t)$, on the viscoelastic supports.

In this case, the boundary conditions are changed and the displacements on the viscoelastic supports are relative to the applied reaction forces, which vary with time. On the other hand, point by point beam accelerations, which cause inertia forces, change the 


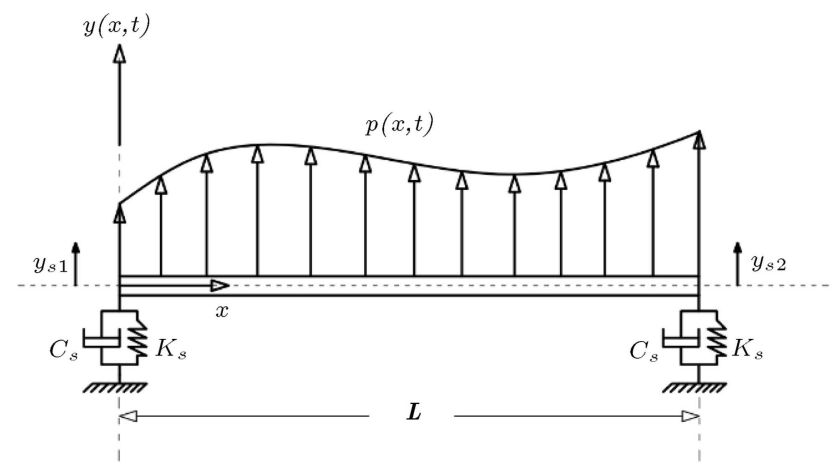

Figure 3. Beam model on viscoelastic supports.

reaction forces as well. Eqs. (13) and (14) show the relation between the reaction forces, $R_{1}$ and $R_{2}$, and stiffness of viscoelastic supports, $K_{s}$, and viscoelastic support damping, $C_{s}$ :

$$
\begin{aligned}
& R_{1}=K_{s} y_{s 1}+C_{s} \dot{y}_{s 1}, \\
& R_{2}=K_{s} y_{s 2}+C_{s} \dot{y}_{s 2},
\end{aligned}
$$

where $y_{s 1}$ and $y_{s 2}$ are the beam displacements on the viscoelastic supports. Hence, they can be written as:

$$
\begin{aligned}
& y_{s 1}=y(0, t), \\
& y_{s 2}=y(L, t) .
\end{aligned}
$$

Different end conditions of the beams can be modeled by using different boundary conditions. For the hinged end condition on the viscoelastic supports, which is assumed in this paper, the second boundary condition is:

$$
\left.\frac{\partial^{2} y(x, t)}{\partial x^{2}}\right|_{x=0}=\left.0 \quad \& \quad \frac{\partial^{2} y(x, t)}{\partial x^{2}}\right|_{x=L}=0 .
$$

\section{Numerical solution}

The beam should be divided into enough tiny elements, in this paper more than 200, depending on different spans. The more the span, the more the number of elements to reach more accurate results; but the analyses last more. Using the finite difference method, Eq. (11) can be solved for an assumed force vector $F_{t i}(t)$, which consists of $\mathbf{F}$. In finite difference method, for the estimation of $y^{(4)}\left(x_{n}, t\right)$, i.e. $\frac{\partial^{4} y}{\partial x^{4}}$, Eqs. (16) and (17), as shown in Box I, can be obtained by Taylor expansion. Eq. (16) estimates $y^{(4)}\left(x_{n}, t\right)$ by the displacement of the five adjacent nodes, but Eq. (17) uses seven adjacent nodes, which is more accurate.

In estimating the second derivative of displacement with respect to time, i.e., $\frac{\partial^{2} y(x, t)}{\partial t^{2}}$, Eq. (18) can be used as:

$$
\frac{\partial^{2} y(x, t)}{\partial t^{2}}=\frac{y\left(x, t_{n-1}\right)-2 y\left(x, t_{n}\right)+y\left(x, t_{n+1}\right)}{\Delta t^{2}} .
$$

In addition, $\mathbf{F}$ must satisfy Eq. (7). This equation can be solved by the Wilson- $\theta$ method to calculate u. The Wilson- $\theta$ method is essentially an extension of the linear acceleration method in which a linear variation of acceleration from time $t$ to time $t+\Delta t$ is assumed [10]. The equation must be satisfied at time $t_{n+\theta}=t_{n}+\theta \Delta t$ with $\theta \geq 1$ :

$$
\mathbf{M} \ddot{\mathbf{u}}_{n+\theta}+\mathbf{C} \dot{\mathbf{u}}_{n+\theta}+\mathbf{K} \mathbf{u}_{n+\theta}=\mathbf{F}_{n+\theta} .
$$

The displacement and velocity at $t_{n+\theta}$ are related to $\mathbf{u}_{\mathbf{n}}, \dot{\mathbf{u}}_{\mathbf{n}}$, and $\ddot{\mathbf{u}}_{\mathbf{n}}$ by Eqs. (20) and (21):

$$
\begin{aligned}
\mathbf{u}_{n+\theta} & =\mathbf{u}_{n}+\theta \Delta t \dot{\mathbf{u}}_{n}+(\theta \Delta t)^{2}[0.5-\beta] \ddot{\mathbf{u}}_{n} \\
& +(\theta \Delta t)^{2} \beta \ddot{\mathbf{u}}_{n+\theta}, \\
\dot{\mathbf{u}}_{n+\theta} & =\dot{\mathbf{u}}_{n}+\theta \Delta t(1-\gamma) \ddot{\mathbf{u}}_{n}+\theta \Delta t \gamma \ddot{\mathbf{u}}_{n+\theta} .
\end{aligned}
$$

By substituting Eqs. (20) and (21) into Eq. (19), $\ddot{\boldsymbol{u}}_{n+\theta}$ can be found by solving the non-linear equation. The acceleration at $t_{n+1}$ is then deduced from $\ddot{\boldsymbol{u}}_{n}$ and $\ddot{\boldsymbol{u}}_{n+\theta}$ by linear interpolation:

$$
\ddot{\mathbf{u}}_{n+1}=\left(1-\frac{1}{\theta}\right) \ddot{\mathbf{u}}_{n}+\left(\frac{1}{\theta}\right) \ddot{\mathbf{u}}_{n+\theta},
$$

from which the displacement and velocity at $t_{n+1}$ can be obtained by using the standard Newmark formulae:

$$
\mathbf{u}_{n+1}=\mathbf{u}_{n}+\Delta t \dot{\mathbf{u}}_{n}+\Delta t^{2}(0.5-\beta) \ddot{\mathbf{u}}_{n}+\Delta t^{2} \beta \ddot{\mathbf{u}}_{n+1},
$$

$$
\begin{aligned}
y^{(4)}\left(x_{n}, t\right) & =\frac{y\left(x_{n-2}, t\right)-4 y\left(x_{n-1}, t\right)+6 y\left(x_{n}, t\right)-4 y\left(x_{n+1}, t\right)+y\left(x_{n+2}, t\right)}{\left(\Delta x^{4}\right)}, \\
y^{(4)}\left(x_{n}, t\right) & =\frac{-\frac{1}{6} y\left(x_{n-3}, t\right)+2 y\left(x_{n-2}, t\right)-\frac{13}{2} y\left(x_{n-1}, t\right)+\frac{28}{3} y\left(x_{n}, t\right)-\frac{13}{2} y\left(x_{n+1}, t\right)+2 y\left(x_{n+2}, t\right)-\frac{1}{6} y\left(x_{n+3}, t\right)}{(\Delta x)^{4}},
\end{aligned}
$$

where $y^{(4)}\left(x_{n}, t\right)$ is the fourth derivative of vertical displacement with respect to $x$. 


$$
\dot{\mathbf{u}}_{n+1}=\dot{\mathbf{u}}_{\mathbf{n}}+\Delta t(1-\gamma) \ddot{\mathbf{u}}_{n}+\Delta t \gamma \ddot{\mathbf{u}}_{n+1}
$$

In the Wilson- $\theta$ method, it is assumed that $\beta=$ $1 / 6$ and $\gamma=1 / 2[10]$. The $\theta$ is often chosen to be 1.42 .

Finally, by using Eq. (12) and displacement vectors, force vector $\mathbf{F}_{t i}(t)$ can be found, which would probably not be same as the $\mathbf{F}_{t i}(t)$ assumed at the beginning of the analysis. That $F_{t i}(t)$ obtained by trial and error is merely a "good" estimate of the accurate value. This process could be done first for each time increment and, afterwards, for each velocity of truck increment to calculate the DAF in a wide range of velocities. The DAF (Dynamic Amplification Factor) is the ratio of maximum dynamic stress, due to a moving vehicle, to maximum static stress, due to constant weight of the vehicle, near the mid-span of the beam.

\section{Maximum dynamic bending stresses}

Regarding strength of materials science, for a beam with symmetric section under bending moment, the equation of maximum bending stress in a particular beam section is:

$$
\left.\sigma_{\max }\right|_{\text {Section }}=-\frac{M(h / 2)}{I},
$$

where $I$ is the second moment of area; $M$ is the bending moment at the specified section; and $h$ is the height of the section. In addition, the bending moment and curvature in the beam have a relation:

$$
M=E I y^{\prime \prime}
$$

By combining Eqs. (25) and (26), $\sigma_{\max }$ can be expressed in the form:

$$
\left.\sigma_{\max }\right|_{\text {Section }}=-E(h / 2) y^{\prime \prime} .
$$

In finite difference method, for the estimation of $y^{\prime \prime}$, i.e. $\frac{\partial^{2} y}{\partial x^{2}}$, Eqs. (28) and (29) can be obtained by Taylor expansion. Eq. (28) estimates $y^{\prime \prime}$ by the displacement of three adjacent nodes, but Eq. (29), as shown in
Box II, uses five adjacent nodes, which is more accurate and is used in this paper for the internal nodes:

$$
\begin{aligned}
y^{\prime \prime}= & \frac{\partial^{2} y\left(x_{n}, t_{m}\right)}{\partial x^{2}}= \\
& \frac{y\left(x_{n-1}, t_{m}\right)-2 y\left(x_{n}, t_{m}\right)+y\left(x_{n+1}, t_{m}\right)}{\Delta x^{2}} .
\end{aligned}
$$

Therefore, to find the maximum bending stress through the beam length, the maximum curvature, i.e. $y^{\prime \prime}$, must be found in each time interval, as shown in Box III.

\section{Vehicle model (case studies)}

The aim of the simulation is to consider a beam in two different situations. First, analyzing the bending stresses in the beam with simple hinged supports as one vehicle passes over; and, second, analyzing the beam on two viscoelastic supports and the same vehicle passes over, with different speeds and different bridge span lengths.

A five-axle European truck model is used to verify and compare the results with [10]. The vehicle parameters are shown in Table 1.

In Table 2, the main beam model parameters, which Cantero [10] used, are listed. Four different beams with lengths of $15,25,35$, and 70 are considered. The section inertia and mass per unit length for each beam length are different and are mentioned in Table 2. The other parameters, like modulus of elasticity and damping, remain the same for all different spans.

The analysis for each beam is conducted with two different road profiles: First, a smooth profile and, second, a sinusoidal road profile with $1 \mathrm{~cm}$ amplitude and $5 \mathrm{~m}$ wave length. The sinusoidal road profiles are calculated because bridge surfaces in real engineering have imperfections and are not smooth because of the construction process.

The vehicle model consists of tractor, semi-trailer, and suspensions (Figure 4). It can be noted that $y_{s}$, i.e. the vertical displacement of the semi-trailer, has a

$$
y^{\prime \prime}=\frac{\partial^{2} y\left(x_{n}, t_{m}\right)}{\partial x^{2}}=\frac{-y\left(x_{n-2}, t_{m}\right)+16 y\left(x_{n-1}, t_{m}\right)-30 y\left(x_{n}, t_{m}\right)+16 y\left(x_{n+1}, t_{m}\right)-y\left(x_{n+2}, t_{m}\right)}{12(\Delta x)^{2}}
$$

Box II

$$
\left.\sigma_{\max }\right|_{\text {beam }}=-E(h / 2) \frac{-y\left(x_{n-2}, t_{m}\right)+16 y\left(x_{n-1}, t_{m}\right)-30 y\left(x_{n}, t_{m}\right)+16 y\left(x_{n+1}, t_{m}\right)-y\left(x_{n+2}, t_{m}\right)}{12(\Delta x)^{2}}
$$


Table 1. Five-axle model parameters.

\begin{tabular}{ll}
\hline Dimensional data $(\mathbf{m})$ & Mass and inertia data \\
\hline$a_{1}=-0.13$ & Tractor sprung mass, $m_{T}: 4500 \mathrm{~kg}$ \\
$a_{2}=1.10$ & Tractor pitch moment of inertia, $I_{T}: 4604 \mathrm{~kg} \cdot \mathrm{m}^{2}$ \\
$b_{1}=0.5$ & Semi-trailer sprung mass, $m_{S}: 31450 \mathrm{~kg}$ \\
$b_{2}=2.5$ & Semi-trailer pitch moment of inertia, $I_{S}: 16302 \mathrm{~kg} \cdot \mathrm{m}^{2}$ \\
$b_{31}=1.30, b_{32}=2.40$ & Tractor front axle unsprung mass, $m_{1}: 700 \mathrm{~kg}$ \\
$b_{33}=3.50$ & Tractor back axle unsprung mass, $m_{2}: 1100 \mathrm{~kg}$ \\
$b_{4}=4.15, b_{5}=2.15$ & Semi-trailer axle unsprung mass, $m_{31}, m_{32}, m_{33}: 750 \mathrm{~kg}$ \\
\hline Spring rates $(\mathbf{k N} / \mathbf{m})$ & Viscous damping rates $(\mathbf{k N s} / \mathbf{m})$ \\
\hline$k_{1}=400$ & $c_{1}=10$ \\
$k_{2}=1000$ & $c_{2}=10$ \\
$k_{31}=k_{32}=k_{33}=750$ & $c_{31}=c_{32}=c_{33}=10$ \\
$k_{t 1}=1750$ & \\
$k_{t 2}=3500$ & \\
$k_{t 31}=k_{t 32}=k_{t 33}=3500$ & \\
\hline
\end{tabular}

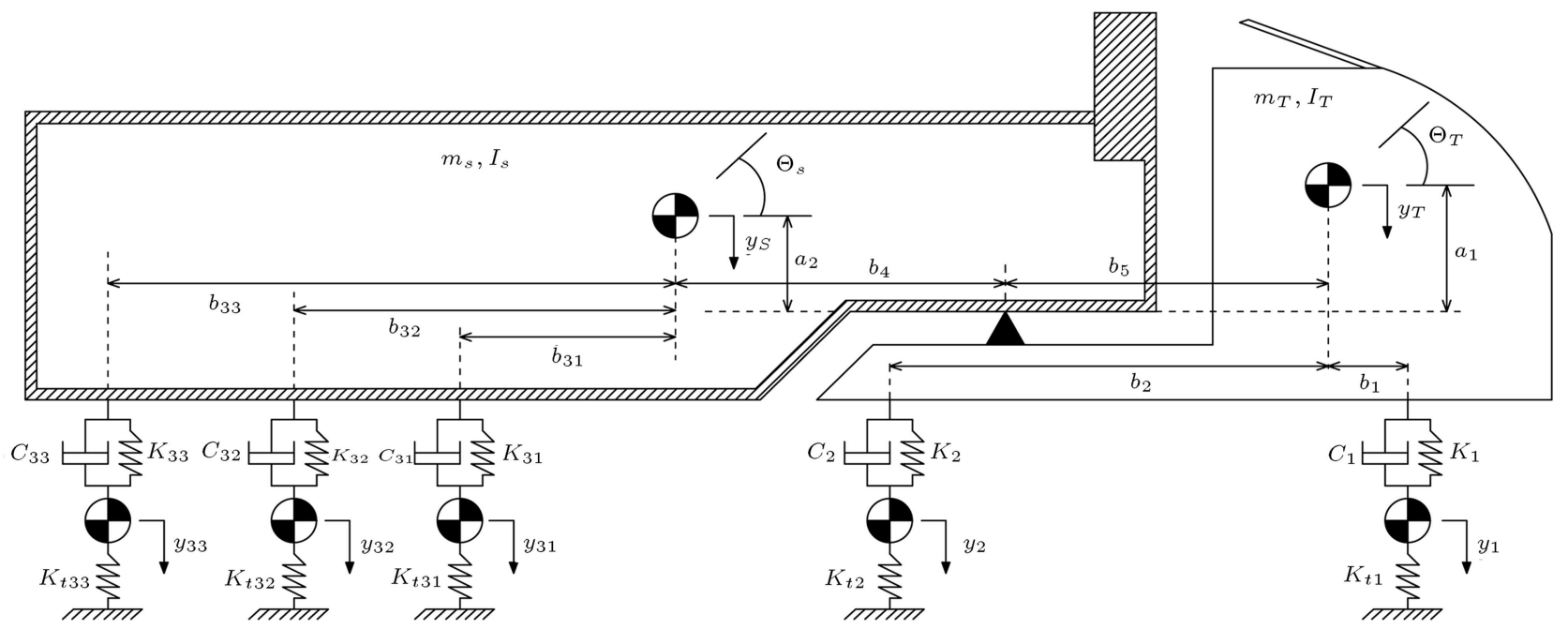

Figure 4. European truck model.

Table 2. Beam model parameters.

\begin{tabular}{|c|c|c|c|}
\hline \multirow{2}{*}{$\mathrm{L}=15 \mathrm{~m}$} & Section inertia, $I$ : & 0.5273 & $\mathrm{~m}^{4}$ \\
\hline & Mass per unit length, $m$ : & 28125 & $\mathrm{~kg} / \mathrm{m}$ \\
\hline \multirow{2}{*}{$\mathrm{L}=25 \mathrm{~m}$} & Section inertia, $I$ : & 1.3901 & $\mathrm{~m}^{4}$ \\
\hline & Mass per unit length, $m$ : & 18358 & $\mathrm{~kg} / \mathrm{m}$ \\
\hline \multirow{2}{*}{$\mathrm{L}=35 \mathrm{~m}$} & Section inertia, $I$ : & 3.4162 & $\mathrm{~m}^{4}$ \\
\hline & Mass per unit length, $m$ : & 21752 & $\mathrm{~kg} / \mathrm{m}$ \\
\hline \multirow{2}{*}{$\mathrm{L}=70 \mathrm{~m}$} & Section inertia, $I$ : & 19.5313 & $\mathrm{~m}^{4}$ \\
\hline & Mass per unit length, $m$ : & 30752 & $\mathrm{~kg} / \mathrm{m}$ \\
\hline
\end{tabular}

For all spans: and Young's modulus,

$E=3.5 \times 10^{10} \mathrm{~N} / \mathrm{m}^{2}$ geometrical relationship:

$$
y_{s}=y_{T}+b_{5} \theta_{T}+b_{4} \theta_{S},
$$

where $y_{T}$ is the vertical displacement of the tractor; $y_{i}$ $(\mathrm{i}=1,2,31,32,33)$ are the vertical displacements of suspensions; and $\theta_{T}$ and $\theta_{S}$ are the pitch of tractor and semi-trailer, respectively.

Consequently, each vehicle model has eight independent degrees of freedom. The equation of motion of the vehicle model can be expressed in the form of Eq. (7). $\mathbf{u}$ and $\mathbf{F}$ are vectors of generalized coordinates and forces for each vehicle model:

$$
\begin{aligned}
& \mathbf{u}=\left\{\begin{array}{llllllll}
y_{T} & \theta_{T} & \theta_{S} & y_{1} & y_{2} & y_{31} & y_{32} & y_{33}
\end{array}\right\}^{T}, \\
& \mathbf{F}=\left\{\begin{array}{ccccc}
0 & 0 & 0 & -\left(F_{t 1}\right) & -\left(F_{t 2}\right) \\
& -\left(F_{t 31}\right) & -\left(F_{t 32}\right) & \left.-\left(F_{t 33}\right)\right\}^{T} &
\end{array}\right.
\end{aligned}
$$

where $F_{\mathrm{ti}}$ is the force under the $t i$ th tire of the vehicle 
applied to the bridge surface. The tires are prevented from uplift (negative force) by the following condition:

$$
\begin{aligned}
\left(F_{t i}\right) & =\left(K_{t i}\right)\left[y_{i}(t)-y_{b r}\left(x_{i}, t\right)+r_{i}(t)\right] \geq 0, \\
i & =1,2,31,32,33,
\end{aligned}
$$

where $y_{b r}\left(x_{i}, t\right)$ is the displacement of the beam and $r_{i}(t)_{j}$ is the road profile underneath the $i$ th axle of the vehicle at instant $t$.

Truck mass matrix, $\mathbf{M}$, stiffness matrix, $\mathbf{K}$, and damping matrix, $\mathbf{C}$, are computed as shown in Box IV [10].

\section{Model validation}

\subsection{Effect of damping [17]}

Finding an appropriate damping value for an actual structure is not easy. To investigate the importance of damping on the bridge response and Dynamic Amplification Factor (DAF), some analyses are performed for a moving truck, described in Figure 4, on a $25-\mathrm{m}$ span bridge, describe in Table 2, with different damping ratios $(1.5 \%, 3 \%, 5 \%$, and $7 \%)$. The results on DAF are presented in Figure 5, showing that the lower the damping ratio, the higher the dynamic response, but in the same shape because the bridge is underdamped, i.e. $\xi \ll 1$.

Cantero [10] calculated the effect of damping on variation of $\mathrm{DAF}$ on the same bridge span. The results differ only less than $2 \%$, which is negligible. The differences in accuracy between the two are due to different time interval sizes and different approaches.

\subsection{Comparison with the published moving oscillator model}

The results obtained by the present numerical method have been compared second with analytically simulated results and published results from the literature. Cantero [10] calculated the maximum dynamic stress on simply supported bridges traversed by moving vehicles. Viscoelastic support and its influences on

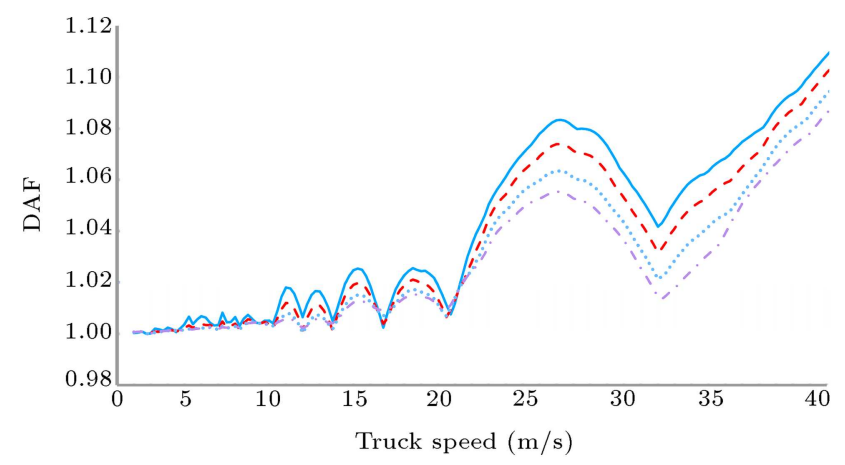

Figure 5. Damping effect of the bridge $(L=25 \mathrm{~m})$ at $1.5 \%$ (solid), $3 \%$ (dashed), $5 \%$ (dotted), and $7 \%$ (dash-dotted).
DAF were not investigated. Thus, this analysis, with the same truck and beams properties, is done to compare the results with the results of Cantero [10] to assure accuracy of the approach. Cantero [10] used the method of finite Fourier integral transformation to separate Eq. (6) by defining the total bending moment in the beam as the sum of two bending moments, which Fryba [2] suggested; but, in this paper, the finite difference method has been used to solve Eq. (6). Furthermore, Cantero and OBrien released a benchmark file to verify their results with the other models. They defined Normalized Bending Moment (NBM) as the ratio of the influence line of bending moment or stress in the middle of the beam to the maximum static bending moment or stress for a moving oscillator problem. They used a moving oscillator problem, shown in Figure 6, and calculated NBM for a 25-m beam, introduced in Table 2, for two different surface profiles, namely, smooth profile and sinusoidal profile, with $1 \mathrm{~cm}$ amplitude and $5 \mathrm{~m}$ wave length. The moving oscillator's properties were: $M=8900$ $\mathrm{kg}, m=1100 \mathrm{~kg}, c=4 E 4 \mathrm{Ns} / \mathrm{m}, 4 K=2 E 6 \mathrm{~N} / \mathrm{m}$, $k=3.5 E 6 \mathrm{~N} / \mathrm{m}, v=30 \mathrm{~m} / \mathrm{s}$.

By using finite difference method and the algorithm described in Section 5, NBMs for the same moving oscillator problem are computed. In Figure 7, the numerically obtained response (NBM) sample has been compared with analytically-numerically simulated response sample found in Cantero [10] for two smooth and sinusoidal road profiles. The comparison of response sample exhibits close agreement between them. The differences are less than $0.5 \%$ and are due to different time interval sizes and different approaches. As a result of this accuracy and verification, the described approach is reliable.

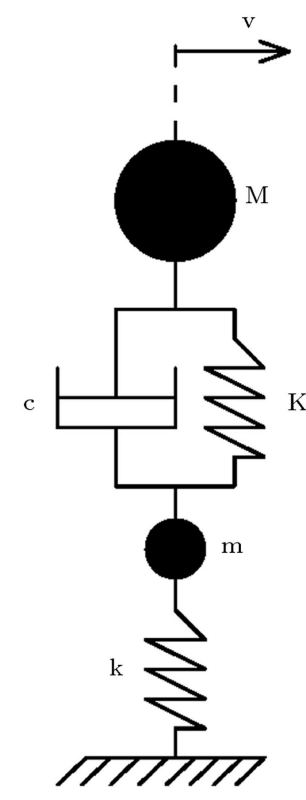

Figure 6. Moving oscillator model. 


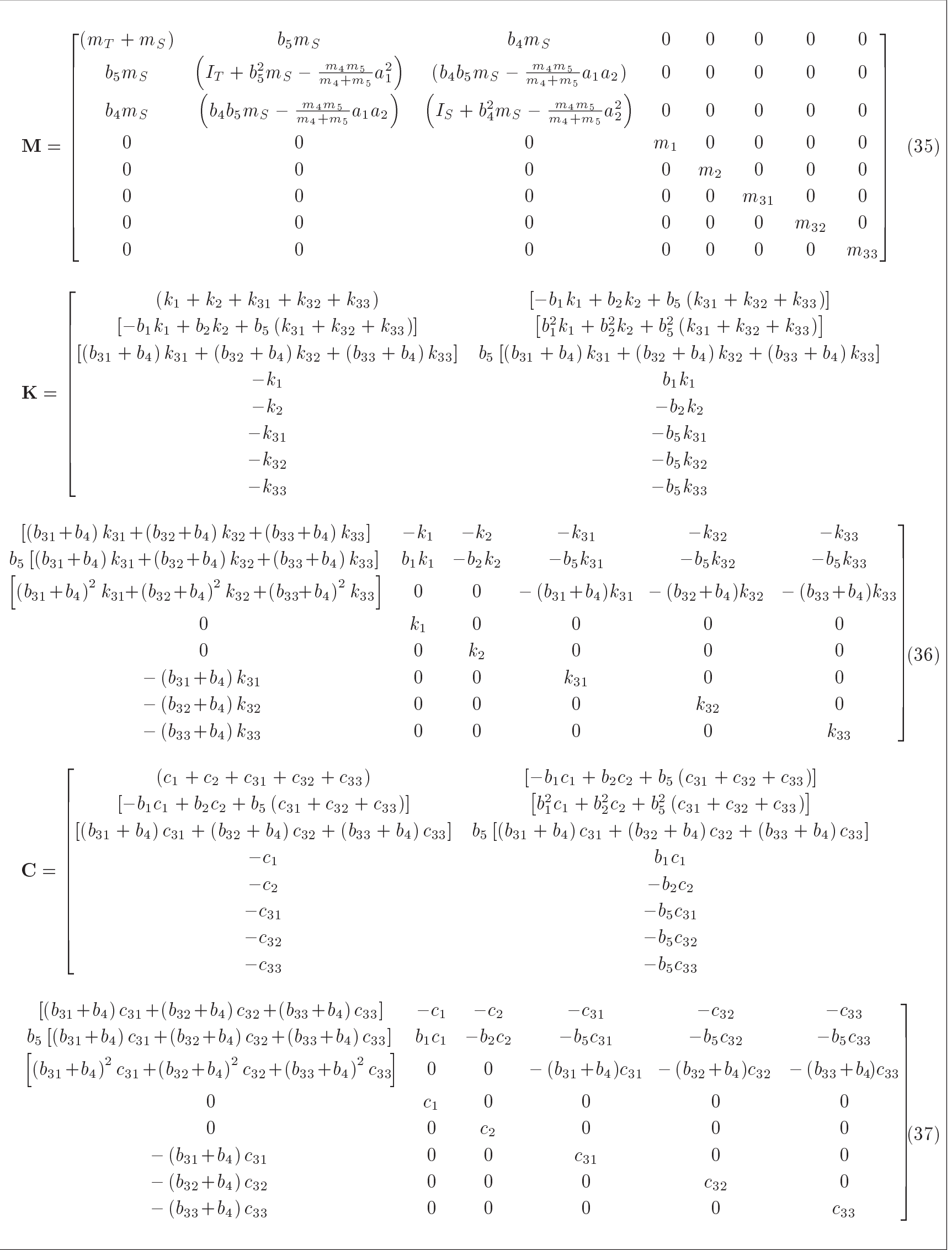




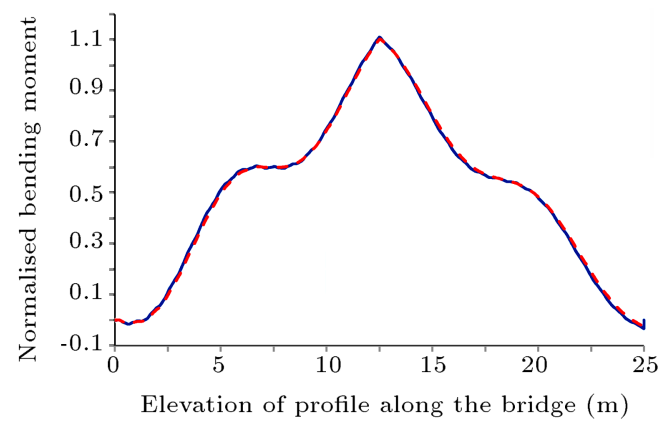

(a)

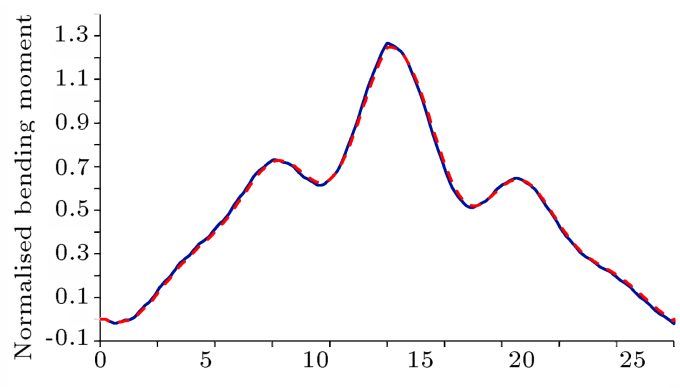

Elevation of profile along the bridge $(\mathrm{m})$

(b)

Figure 7. Verifying the model with Cantero et al. [10] for a 25-m bridge.

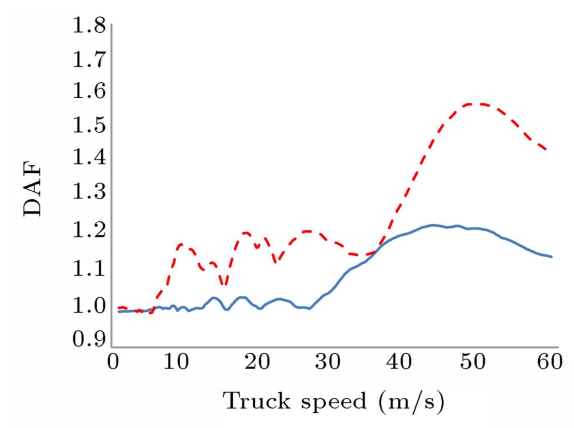

(a) $L=15 \mathrm{~m}$

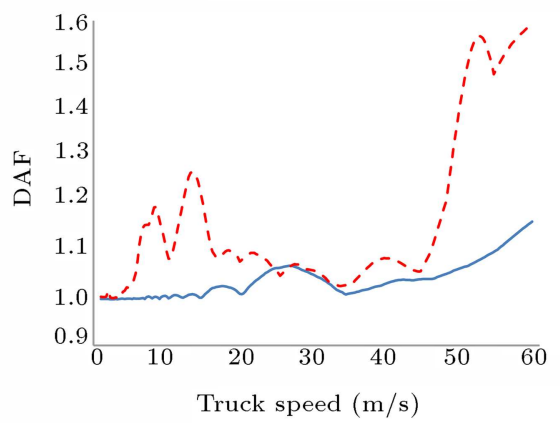

(c) $L=35 \mathrm{~m}$

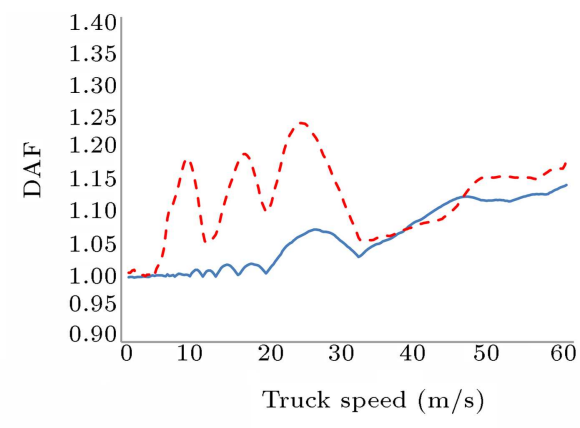

(b) $L=25 \mathrm{~m}$

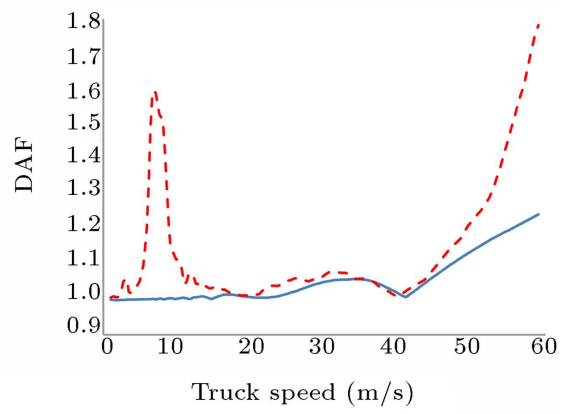

(d) $L=70 \mathrm{~m}$

Figure 8. Influence of truck speed on DAF at smooth profile (solid) and sinusoidal profile (dashed).

\section{Results and discussions}

\subsection{Assumptions and analyses of different simply supported bridges}

Simulations were carried out to analyze the influence of speed, bridge length; and road profile on the Dynamic Amplification Factors (DAfs). Critical Influential Speed (CIS) is defined as the speed of moving truck in which the beam experiences the maximum Dynamic Amplification Factor (DAF) with respect to time variation. According to the results, CIS can be obtained by scrutinizing the variations of DAF with respect to variations of speed for the moving truck. In order to examine the presented numerical method for moving truck problems and also obtain the CIS values at the same time, the method was carried out for beams, described in Table 2 .

The speed increases in $0.25 \mathrm{~m} / \mathrm{s}$ intervals between
1 to $60 \mathrm{~m} / \mathrm{s}(3.6$ to $216 \mathrm{~km} / \mathrm{hr})$ and the damping ratio is assumed $3 \%$ in the analyses. The analysis for each beam is conducted with two different road profiles: first, a smooth profile and, second, a sinusoidal road profile with $1 \mathrm{~cm}$ amplitude and $5 \mathrm{~m}$ wave length. Furthermore, the bridge spans are suggested to be 15 , 25, 35, and 70 (4 cases). Each simulation contains a fully dynamic problem with 8-DOF moving truck with different speeds on a beam with several nodes and the total passing time divided into more than 2000 intervals. The beam is divided into 200 elements for 15- and 25-m spans and 300 elements for 35 and $70-$ $\mathrm{m}$ spans. The time the vehicle passes the entire beam is divided into 2000, for short span and high speed, to 7000 , for long span and low speed, time intervals depending on the speed of the truck and the beam span. The results are shown in Figure 8.

In Figure 8(a), the influence of speed of a truck, 
described in Figure 4 and Table 1, passing on a 15$\mathrm{m}$ bridge with two different kinds of surface profile (smooth and sinusoidal wave) on DAF is presented. As can be seen, the DAF's are nearly 1 in low speed (like static loading) and increase when the speed increases. The DAF increases at some critical speeds because of the resonance phenomenon, when the loading frequency is near the natural frequency of the bridge. However, the higher the truck speeds, the higher the dynamic response of the bridge (DAF), in general. In addition, the sinusoidal wave surface profile, rather than smooth profile, has a considerable role in having a larger DAF. For the 15-m smooth beam, the maximum DAF is 1.24 , which occurs at the speed of $44 \mathrm{~m} / \mathrm{s}$ (CIS). In addition, for the same length of the bridge but with a sinusoidal road surface, the maximum DAF is 1.58 at the CIS $=50.5 \mathrm{~m} / \mathrm{s}$.

The influence of the speed of a truck passing a 25-m bridge on DAF is presented in Figure 8(b). The same condition is seen and in this case, for the smooth beam, the maximum DAF is 1.14 , which occurs at $60 \mathrm{~m} / \mathrm{s}$ of speed and, for the sinusoidal beam, the maximum DAF is 1.24 at the CIS $=24 \mathrm{~m} / \mathrm{s}$. The results show that the DAF tends to increase in general, but some local maximum points occur, which are due to forcing frequencies when they are too close to the natural vibration frequencies of the bridge beam.

Figure 8(c) and (d) present the influence of speed on 35-m and 70-m bridges, respectively. Again, some local maximum points occur, which are due to the resonance phenomenon.

The existing bridge design codes of a conservative nature are still adequate for designing highway bridges at normal traffic speeds. For instance, AASHTO defines a factor called Dynamic Load Allowance (IM). The static effects of the design truck shall increase by 1.33 for the dynamic load allowance. This approach is conservative at normal truck speeds on a smooth surface profile, but when the trucks with higher speeds moving on an unsmooth road profile are considered, the problem becomes more complicated [17]. In this case, the dynamic load allowance or impact factor may increase up to more than 1.5 as illustrated in Figure 8(a), (c) and (d).

In addition, it must be noted that the damping effect of soil when in contact with some buried structural components such as footings can decrease the real dynamic load allowance, but it is not considered in this analysis.

\subsection{Effect of truck speed, bridge span, and smoothness of the road profile}

The span length of the bridge is an important factor, which determines DAF or the impact factor in most of the bridge design codes. Combined effect of bridge span and speed of the truck on DAF is not fully identified. Figure 8 (solid line) shows the DAF with variations of velocity and bridge span. It has been found that when the bridge span increases from 15 to $70 \mathrm{~m}$, the maximum DAF decreases by the amount of $10 \%$ when the truck speed is between $30 \mathrm{~m} / \mathrm{s}$ and $45 \mathrm{~m} / \mathrm{s}$. Although increasing span shows a decreasing trend in DAF similar to the earlier studies, when the speed is less than $30 \mathrm{~m} / \mathrm{s}$, the increment found in the present case is not very significant for the span range of $15-70 \mathrm{~m}$ [18].

Surface smoothness and speed of the truck are the two most influential factors that can cause increased dynamic amplification factor and rapid degradation of the bridge. Bridge dynamic amplification factor has been found by changing bridge surface smoothness from smooth condition to sinusoidal condition as mentioned before with change in truck speed. Figure 8 (dashed line) shows that sinusoidal condition of road induces more dynamic bending stress in the bridge when the truck moves over it and it can be catalyzed by truck speed. Resonance phenomenon can cause significant increases of DAF in some local critical speeds, for instance near $7 \mathrm{~m} / \mathrm{s}$ truck speed in $70-\mathrm{m}$ bridge span.

\subsection{Effect of viscoelastic supports}

To consider the effect of viscoelastic support, the damping of the viscoelastic supports is assumed 5, 10, $25,50,100$, and 250 million $\mathrm{Ns} / \mathrm{m}$ (6 viscoelastic cases + simply supported case). To consider the stiffness of viscoelastic supports, it is assumed that the initial displacements of the beam only due to the beam weight are $2,5,10,25$, and $50 \mathrm{~mm}$. Thus, the stiffness of the viscoelastic supports is assumed for 6 cases ( 5 viscoelastic cases + simply supported case). Hence, the stiffness of the viscoelastic supports, $K_{\text {Support }}$, can be taken from Eq. (38):

$$
k_{\text {Support }}=\frac{\mu g L}{2 \Delta_{\text {initial }}},
$$

where $\mu$ is the constant mass per unit length of the beam; $L$ is bridge span length; $g$ is the gravity acceleration, assumed $9.81 \mathrm{~m} / \mathrm{s}^{2}$; and $\Delta_{\text {Initial }}$ is the initial displacement of the beam on the supports.

The truck speed increases in $0.25 \mathrm{~m} / \mathrm{s}$ intervals between 1 to $60 \mathrm{~m} / \mathrm{s}$ (237 cases). The bridge spans are suggested to be $15,25,35$, and 70 (4 cases) and two different kinds of surface profile (smooth and sinusoidal wave) are considered. Therefore, the number of moving truck simulations are:

$$
\begin{aligned}
& 6 \times 5 \times 237 \times 4 \times 2(\text { Viscoelastic })+1 \times 237 \times 4 \\
& \times 2(\text { Hinged })=58776 .
\end{aligned}
$$

Again, each simulation contains a fully dynamic problem with 8-DOF moving truck with different speeds on 


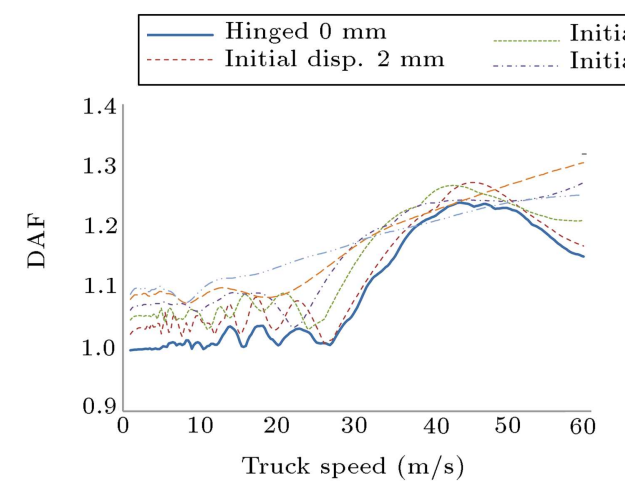

(a) $c=5 \mathrm{E} 6 \mathrm{Ns} / \mathrm{m}$

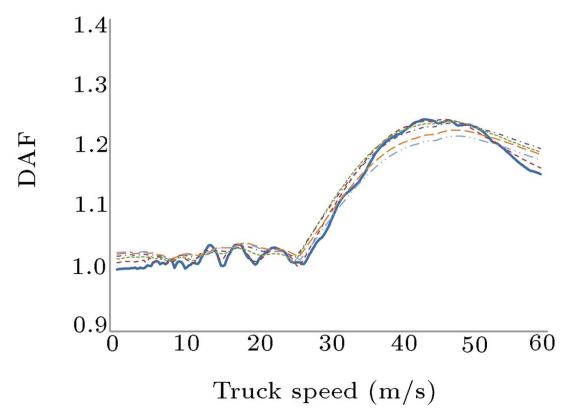

(c) $c=25 \mathrm{E} 6 \mathrm{Ns} / \mathrm{m}$

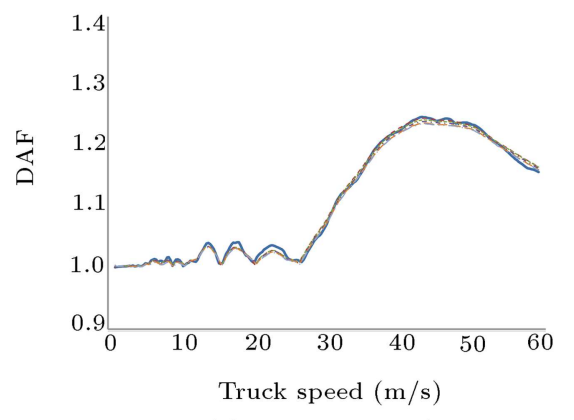

(e) $c=100 \mathrm{E} 6 \mathrm{Ns} / \mathrm{m}$

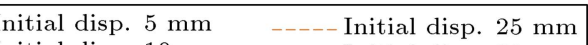

disp. $10 \mathrm{~mm} \quad \ldots$ Initial disp. $50 \mathrm{~mm}$

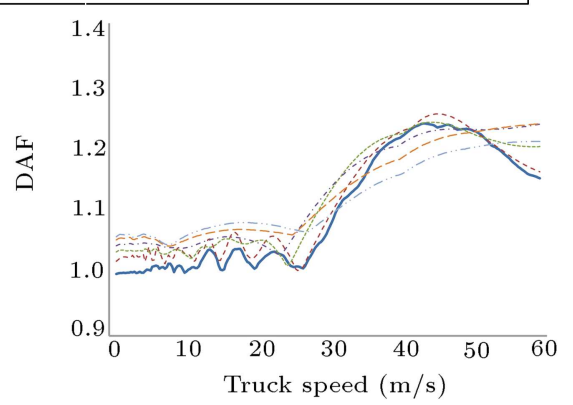

(b) $c=10 \mathrm{E} 6 \mathrm{Ns} / \mathrm{m}$

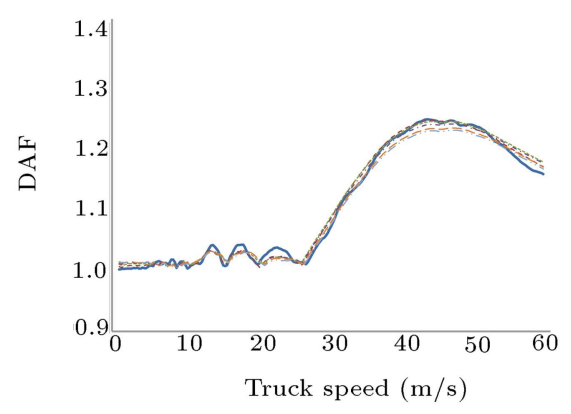

(d) $c=50 \mathrm{E} 6 \mathrm{Ns} / \mathrm{m}$

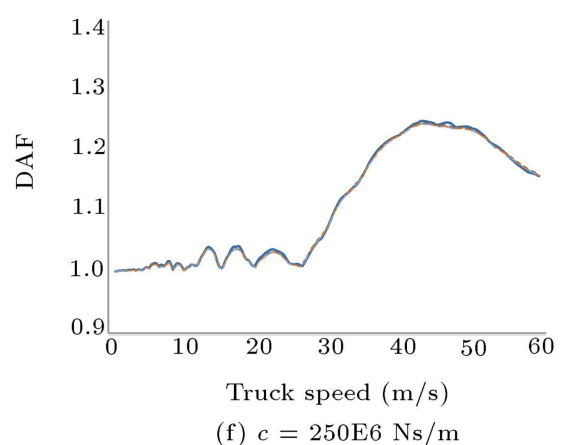

Figure 9. Influence of stiffness and damping of viscoelastic supports and truck speed on DAF of the 15 -m bridge with smooth profile

a beam with several nodes and the total passing time divided into more than 2000 intervals. Furthermore, the beam is divided into 200 elements for 15 - and $25-\mathrm{m}$ spans and 300 elements for 35 and $70-\mathrm{m}$ spans. The time the vehicle passes the entire beam is divided into 2000 , for short span and high speed, to 7000, for long span and low speed, time intervals depending on the speed of the truck and the beam span. The results are presented in Figures 9-16.

Figure 9(a)-(f) show the influence of viscoelastic support, the damping and stiffness of the viscoelastic supports, and truck speed on DAF of the bridge for 15-m bridge having smooth road profile. As can be seen, the DAF tends to increase in general, but some local maximum points could be seen, which are due to forcing frequencies too close to the natural vibration frequencies of the bridge beam.

Figure 10 shows the influence of viscoelastic support, the damping and stiffness of the viscoelastic supports, and truck speed on DAF of the bridge for 15-m bridge having sinusoidal road profile.

In Figure 9, for the smooth road profile of the $15-\mathrm{m}$ hinged bridge, the maximum DAF is 1.240 at the truck speed of $44 \mathrm{~m} / \mathrm{s}$. It can be seen that for the cases with damping equal to or less than $25 \mathrm{E} 6$ $\mathrm{Ns} / \mathrm{m}$, see Figure 9(a)-(c), the viscoelastic supports not only do not decrease the DAF but also increase the DAF because of lack of stability and large displacements, particularly in the cases with low stiffness on viscoelastic supports. In Figure 9(d)-(f), the DAFs in the cases with viscoelastic supports are a little less than DAFs in simply supported bridges, but the differences are not significant; therefore, it may not be justifiable to use viscoelastic supports in the smooth road profile of $15-\mathrm{m}$ bridge. In Figure 10, for the sinusoidal road profile of the $15-\mathrm{m}$ bridge span, the 


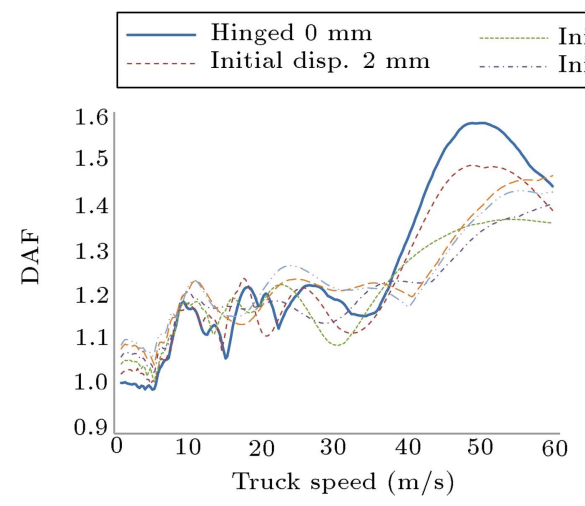

(a) $c=5 \mathrm{E} 6 \mathrm{Ns} / \mathrm{m}$

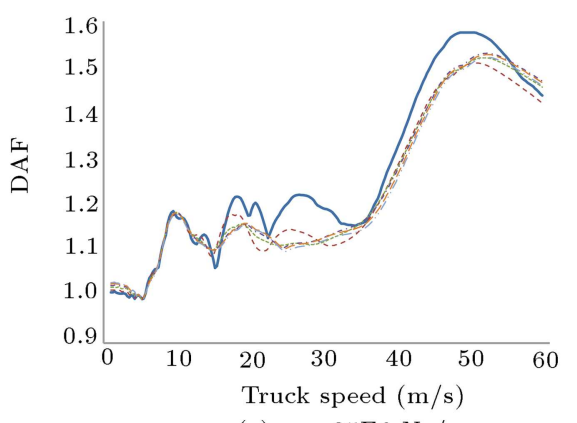

(c) $c=25 \mathrm{E} 6 \mathrm{Ns} / \mathrm{m}$

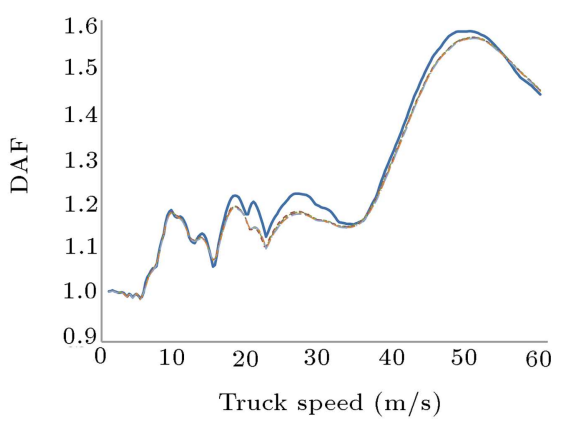

(e) $c=100 \mathrm{E} 6 \mathrm{Ns} / \mathrm{m}$ nitial disp. $5 \mathrm{~mm} \quad \ldots--$ Initial disp. $25 \mathrm{~mm}$ Initial disp. $10 \mathrm{~mm} \quad \ldots \ldots$ Initial disp. $50 \mathrm{~mm}$

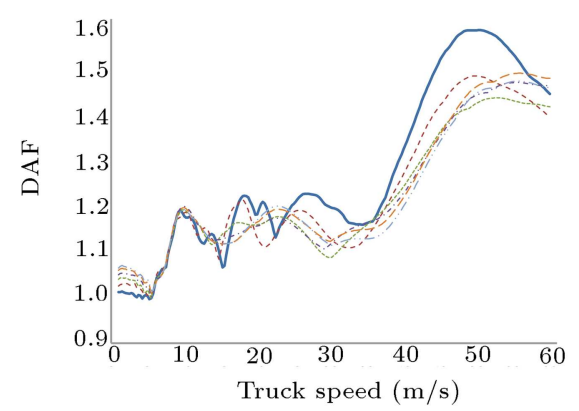

(b) $c=10 \mathrm{E} 6 \mathrm{Ns} / \mathrm{m}$

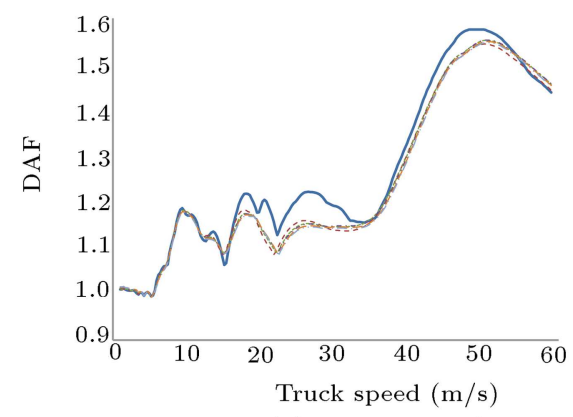

(d) $c=50 \mathrm{E} 6 \mathrm{Ns} / \mathrm{m}$

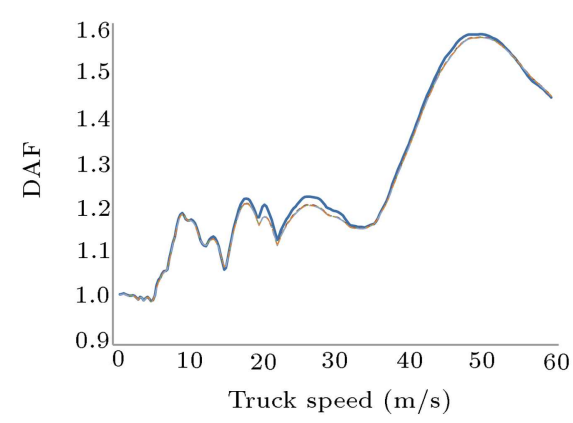

(f) $c=250 \mathrm{E} 6 \mathrm{Ns} / \mathrm{m}$

Figure 10. Influence of stiffness and damping of viscoelastic supports and truck speed on DAF of the 15-m bridge with sinusoidal profile.

maximum DAF of hinged beam is 1.576 at the truck speed $50.5 \mathrm{~m} / \mathrm{s}$.

It can be seen that for the cases with damping equal to $5 \mathrm{E} 6 \mathrm{Ns} / \mathrm{m}$, see Figure 10(a), the viscoelastic supports do not decrease the DAF because of the large displacements on supports, which causes more stresses in the body of the bridge. Figure 10(b)-(f) show that by increasing the damping of viscoelastic supports, the differences between the graphs with different values of stiffness decrease and the viscoelastic graphs get closer to the graph of simply supported bridge. By scrutinizing the obtained graphs, the proposed damping and initial displacements, which are related to stiffness of supports by Eq. (38), of viscoelastic supports are c $=25-50 \mathrm{E} 6 \mathrm{Ns} / \mathrm{m}$ and initial supports displacement due to bridge weight is $2-50 \mathrm{~mm}$. As can be seen in Figure $10(\mathrm{c})$ and (d), the DAFs in viscoelastic supports are about $4 \%$ less than the DAFs in simply supported bridge.

Figurs 11 and 12 present the influence of viscoelastic support and the damping and stiffness of the viscoelastic supports on $25-\mathrm{m}$ bridge, described in Table 2, for two smooth and sinusoidal road profiles, respectively.

As can be seen in Figure 11, for the smooth road profile of the $25-\mathrm{m}$ bridge span, there are two local maximum points for DAF. One local maximum DAF is 1.073 at the truck speed of $26.25 \mathrm{~m} / \mathrm{s}$ and the other local maximum DAF is 1.1236 at the truck speed of 46.5 $\mathrm{m} / \mathrm{s}$. It can be seen that for the cases with damping equal to or less than 5 E6 Ns/m, see Figure 11(a), the viscoelastic supports increase the DAF because of the lack of stability and large displacements, particularly in the cases with low stiffness, on viscoelastic supports. 


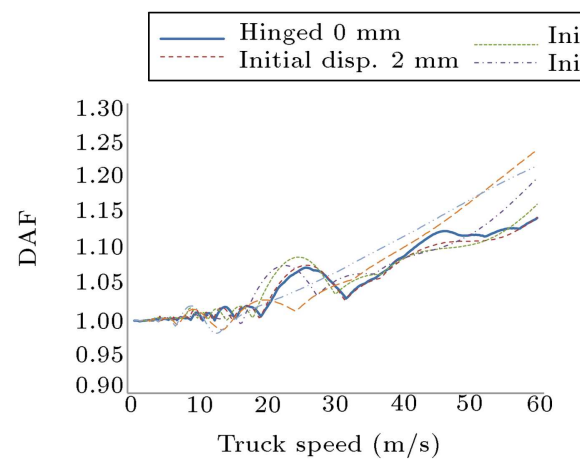

(a) $c=5 \mathrm{E} 6 \mathrm{Ns} / \mathrm{m}$

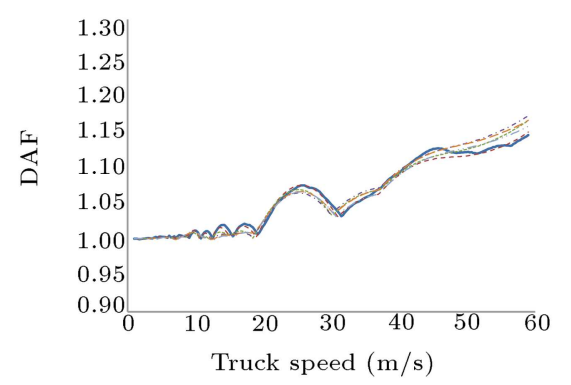

(c) $c=25 \mathrm{E} 6 \mathrm{Ns} / \mathrm{m}$

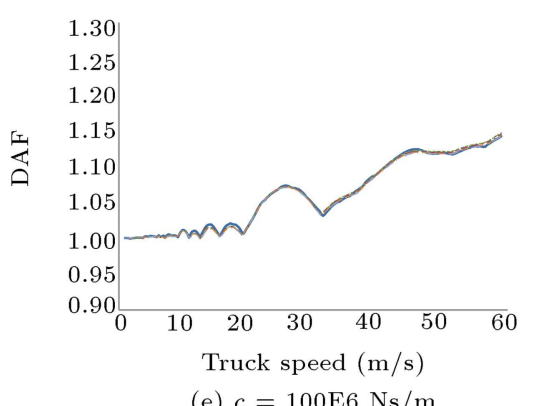

nitial disp. $5 \mathrm{~mm}$ Initial disp. $10 \mathrm{~mm}$-.... Initial disp. $50 \mathrm{~mm}$

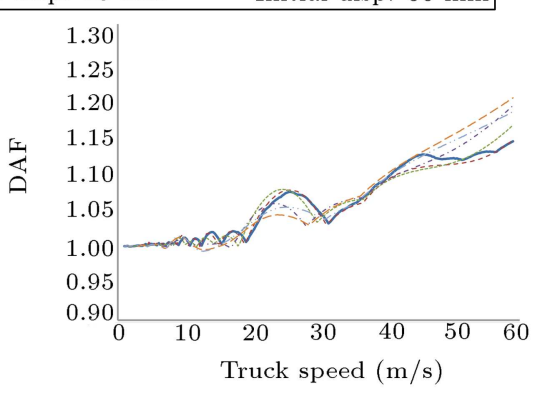

(b) $c=10 \mathrm{E} 6 \mathrm{Ns} / \mathrm{m}$

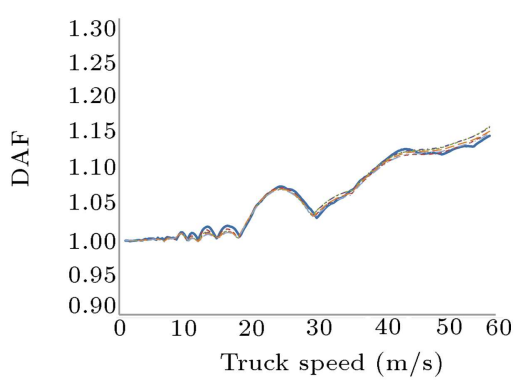

(d) $c=50 \mathrm{E} 6 \mathrm{Ns} / \mathrm{m}$

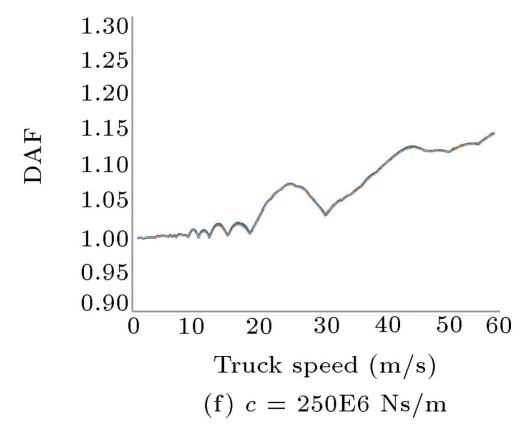

Figure 11. Influence of stiffness and damping of viscoelastic supports and truck speed on DAF of the 25-m bridge with smooth profile.

In Figure 11(b)-(f), the DAFs in the cases with viscoelastic supports are a little less than DAFs in simply supported bridge, but the differences are not significant and, same as in 15-m bridge, it is not justifiable to use viscoelastic supports in the smooth road profile of 25$\mathrm{m}$ bridge in order to observe a tangible reduction in dynamic amplification factor in the bridge.

In Figure 12, for the sinusoidal road profile of the $25-\mathrm{m}$ bridge span, there are three local maximum points for DAF. The first local maximum DAF is 1.183 at the truck speed of $9 \mathrm{~m} / \mathrm{s}$, the second local maximum DAF is 1.189 at the truck speed of $16.75 \mathrm{~m} / \mathrm{s}$, and the third local maximum DAF is 1.237 at the truck speed of $24 \mathrm{~m} / \mathrm{s}$. It can be seen that for the cases with damping equal to or less than $5 \mathrm{E} 6 \mathrm{Ns} / \mathrm{m}$, see Figure 12(a), again the viscoelastic supports do not decrease the DAF because of the large displacements on supports, which causes more stresses in the body of bridge. Figure 12(b)-(f) show that by increasing the damping of viscoelastic supports, the differences between the graphs with different values of stiffness decrease and the viscoelastic graphs get closer to the graph of simply supported bridge. Again, by scrutinizing the obtained graphs, the proposed damping and initial displacements, which are related to stiffness of supports by Eq. (38), of viscoelastic supports are $c=25-50 E 6 \mathrm{Ns} / \mathrm{m}$ and initial supports displacement due to bridge weight is $5-50 \mathrm{~mm}$. For viscoelastic supports with damping equal to or more than 100 E6 $\mathrm{Ns} / \mathrm{m}$, the graphs get closer to the graph of simply supported bridge and no significant reduction in DAFs is observed. Consequently, as can be seen in Figure 12(c) and (d), for the speeds more than $15 \mathrm{~m} / \mathrm{s}$, the local maximum DAFs in the beam with viscoelastic supports are about $5 \%$ less than the local maximum DAFs in simply supported bridge.

Figures 13 and 14 present the influence of viscoelastic supports characteristics, i.e. the damping and the stiffness of the viscoelastic supports, on 35$\mathrm{m}$ bridge for two smooth and sinusoidal road profiles, 


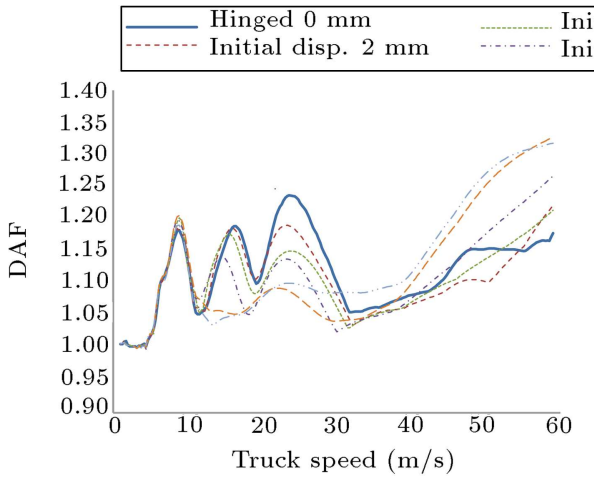

(a) $c=5 \mathrm{E} 6 \mathrm{Ns} / \mathrm{m}$

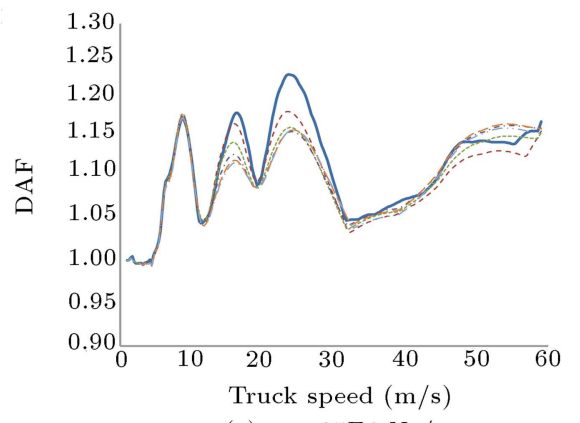

(c) $c=25 \mathrm{E} 6 \mathrm{Ns} / \mathrm{m}$

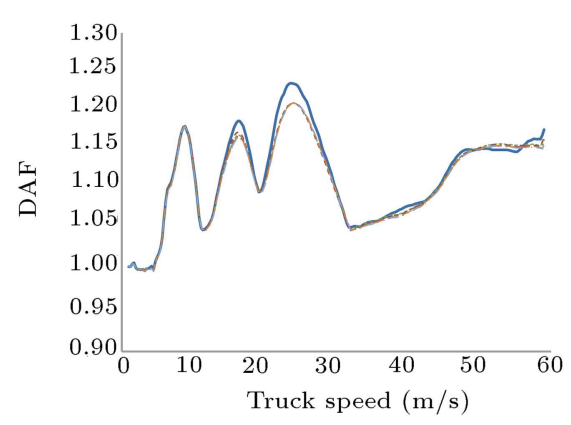

(e) $c=100 \mathrm{E} 6 \mathrm{Ns} / \mathrm{m}$

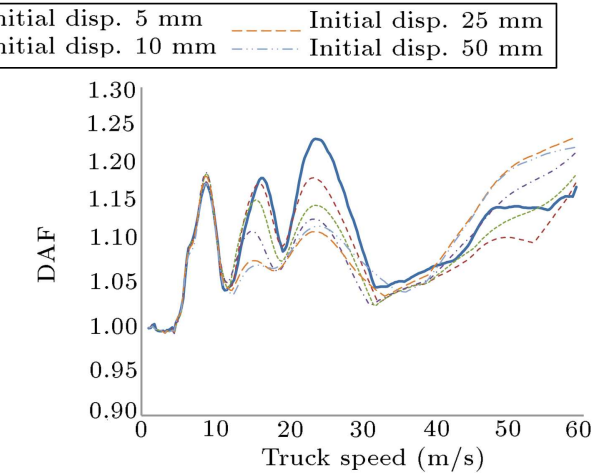

(b) $\mathrm{c}=10 \mathrm{E} 6 \mathrm{Ns} / \mathrm{m}$

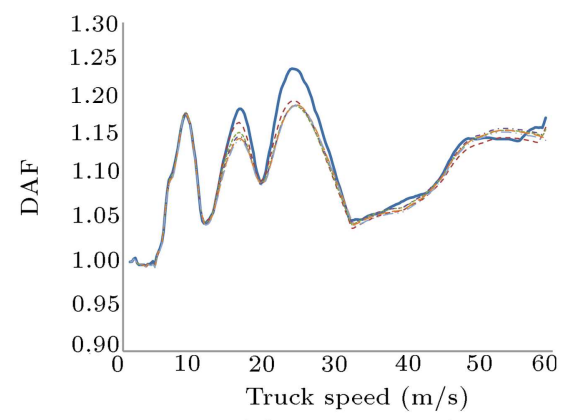

(d) $\mathrm{c}=50 \mathrm{E} 6 \mathrm{Ns} / \mathrm{m}$

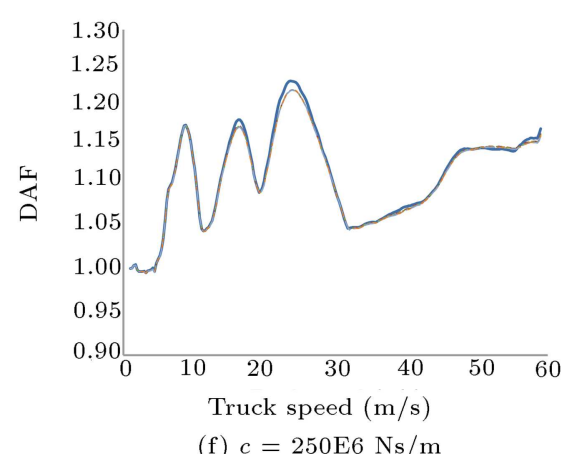

Figure 12. Influence of stiffness and damping of viscoelastic supports and truck speed on DAF of the 25 -m bridge with sinusoidal profile.

respectively. Once more, in Figure 13, which shows the DAFs of the smooth $35-\mathrm{m}$ bridge span, there are no significant reductions in DAFs observed by using viscoelastic supports compared to simply hinged supports. Figure 14 shows the DAFs of the sinusoidal 35-m bridge span and the proposed damping and initial displacements of viscoelastic supports are $c=25-100$ E6 $\mathrm{Ns} / \mathrm{m}$ and initial supports displacement due to bridge weight is $5-50 \mathrm{~mm}$. Furthermore, the DAFs reductions in sinusoidal road profile for $35-\mathrm{m}$ bridge are not significant. The reductions due to using viscoelastic supports are between $0.5 \%$ to $1.5 \%$ depending on stiffness of viscoelastic supports. As a result, based on these case studies, the viscoelastic supports effects on DAF reduction may become less significant when the span of bridges increases.

Figurs 15 and 16 present the influence of viscoelastic supports characteristics on $70-\mathrm{m}$ bridge for two smooth and sinusoidal road profiles, respectively. No significant reductions are observed in the cases of viscoelastic supports in comparison with simply hinged supports in both smooth and sinusoidal road profile graphs. The reductions due to using viscoelastic supports are less than $0.5 \%$ in both Figures 15-16.

Consequently, based on four case studies, which are described in Table 2; the moving European truck described in Table 1; and the use of viscoelastic supports, compared with simply hinged supports, it is seen that reductions in the DAFs for optimum damping and stiffness of viscoelastic supports are about $5 \%$ in the cases of short and medium spans and no significant reduction is observed for long spans.

Furthermore, the reduction in DAFs by using viscoelastic supports is tangible in the case of sinusoidal road profile and in the case of smooth road profile no significant reduction is observed. 


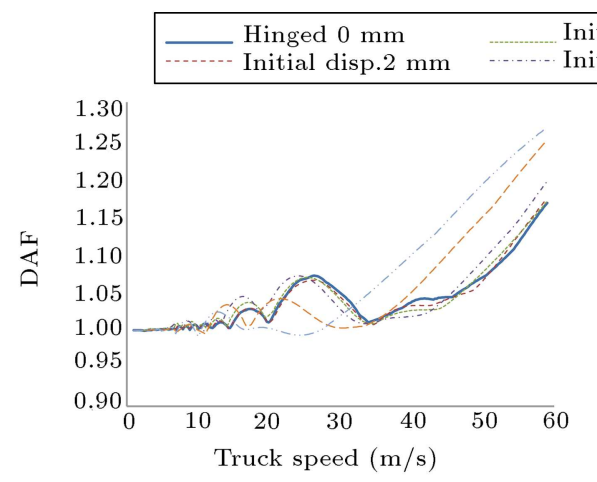

(a) $c=5 \mathrm{E} 6 \mathrm{Ns} / \mathrm{m}$

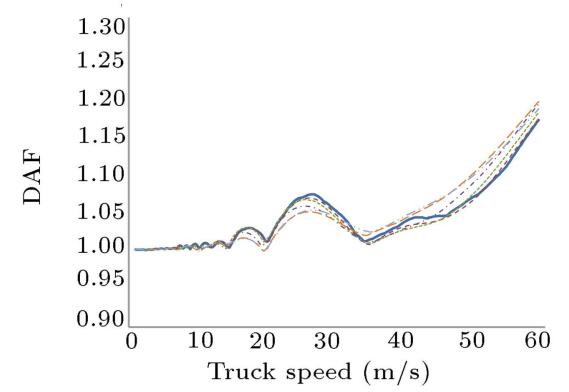

(c) $c=25 \mathrm{E} 6 \mathrm{Ns} / \mathrm{m}$

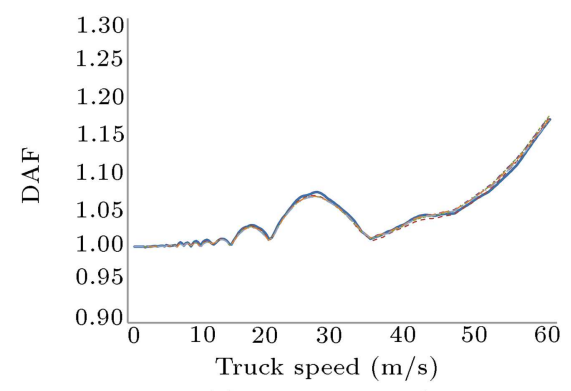

(e) $c=100 \mathrm{E} 6 \mathrm{Ns} / \mathrm{m}$

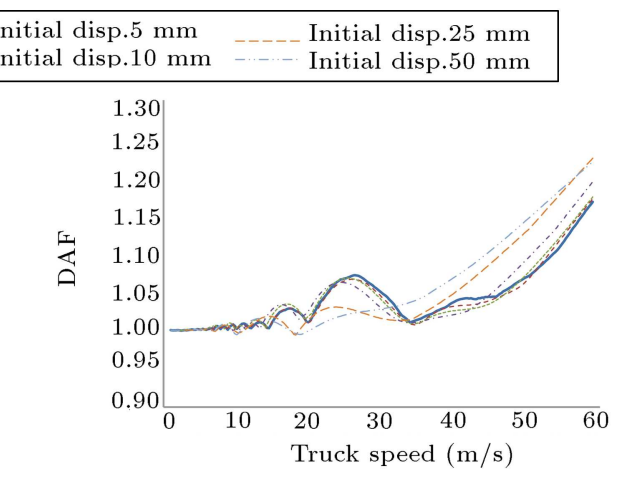

(b) $c=10 \mathrm{E} 6 \mathrm{Ns} / \mathrm{m}$

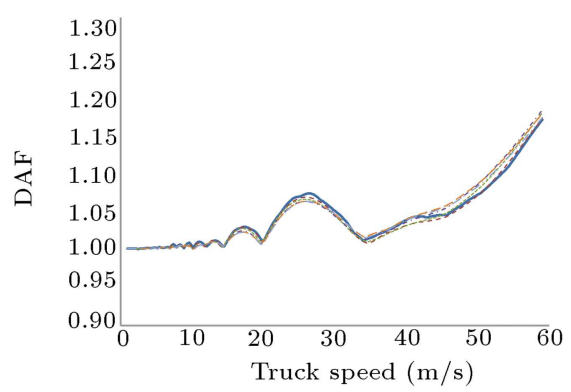

(d) $c=50 \mathrm{E} 6 \mathrm{Ns} / \mathrm{m}$

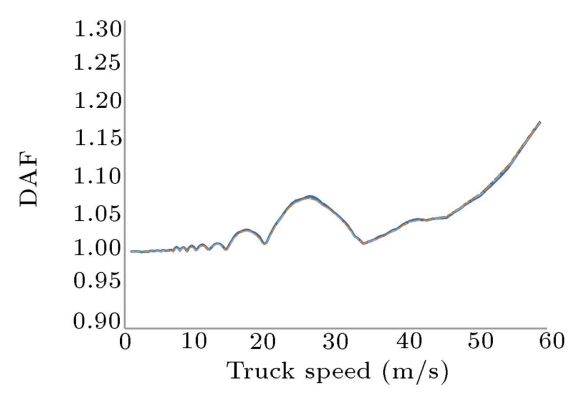

(f) $c=250 \mathrm{E} 6 \mathrm{Ns} / \mathrm{m}$

Figure 13. Influence of stiffness and damping of viscoelastic supports and truck speed on DAF of the 35-m bridge with smooth profile

Table 3. The summary of results and the maximum DAF of different bridge spans and truck speeds.

\begin{tabular}{lccccc}
\hline & & $\boldsymbol{L}=\mathbf{1 5} \mathbf{~ m}$ & $\boldsymbol{L}=\mathbf{2 5} \mathbf{~ m}$ & $\boldsymbol{L}=\mathbf{3 5} \mathbf{~ m}$ & $\boldsymbol{L}=\mathbf{7 0} \mathbf{~ m}$ \\
\cline { 3 - 6 } Recommended $c(\mathrm{Ns} / \mathrm{m})$ & $\begin{array}{l}\text { Smooth or } \\
\text { sinusoidal }\end{array}$ & $25-50 \mathrm{E} 6$ & $25-50 \mathrm{E} 6$ & $25-100 \mathrm{E} 6$ & $10-250 \mathrm{E} 6$ \\
Recommended initial & $\begin{array}{l}\text { Smooth or } \\
\text { sinusoidal }\end{array}$ & $2-50$ & $5-50$ & $5-50$ & $2-50$ \\
displacement on & & & & \\
supports $(\mathrm{mm})$ & $<1 \%$ & $<0.5 \%$ & $<0.25 \%$ & $<0.25 \%$ \\
Percent of DAF reduction & $\begin{array}{l}\text { Smooth } \\
\text { sinusoidal }\end{array}$ & $4 \%$ & $5 \%$ & $0.5 \%-1.5 \%$ & $<0.5 \%$ \\
\hline
\end{tabular}

\subsection{DAF variations and characteristics of the proposed viscoelastic supports}

The results considering viscoelastic supports are summarized in Table 3 for the two different road profiles. One of the most important parts of the results is the amount of DAF reduction observed by using viscoelastic supports.
Since dynamic amplification factor depends on several variables, in this section, the results of viscoelastic supports considering different speeds for the truck moving on the bridge are investigated. The first and second rows of Table 3 show the proposed damping and stiffness, see Eq. (38), of viscoelastic supports, which cause maximum DAF reduction in 


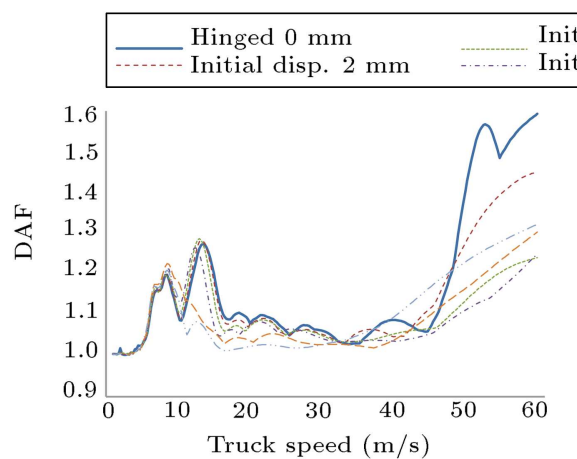

(a) $c=5 \mathrm{E} 6 \mathrm{Ns} / \mathrm{m}$

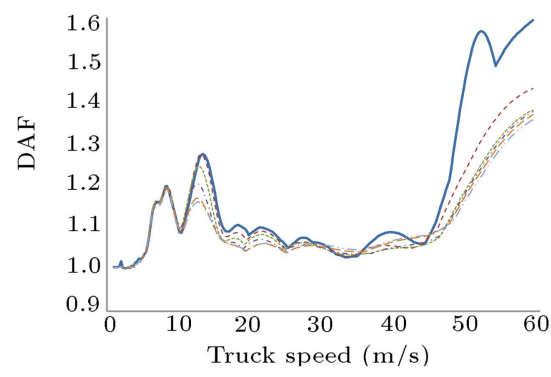

(c) $c=25 \mathrm{E} 6 \mathrm{Ns} / \mathrm{m}$

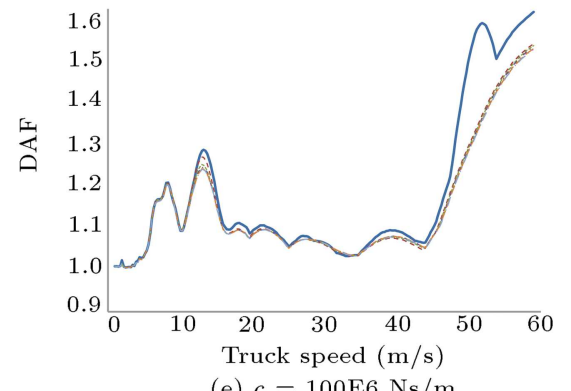

(e) $c=100 \mathrm{E} 6 \mathrm{Ns} / \mathrm{m}$ nitial disp. $5 \mathrm{~mm} \quad$ Initial disp. $25 \mathrm{~mm}$

nitial disp. $10 \mathrm{~mm} \quad$ Initial disp. $50 \mathrm{~mm}$

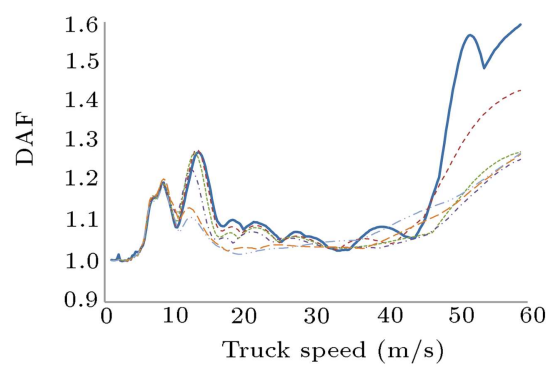

(b) $c=10 \mathrm{E} 6 \mathrm{Ns} / \mathrm{m}$

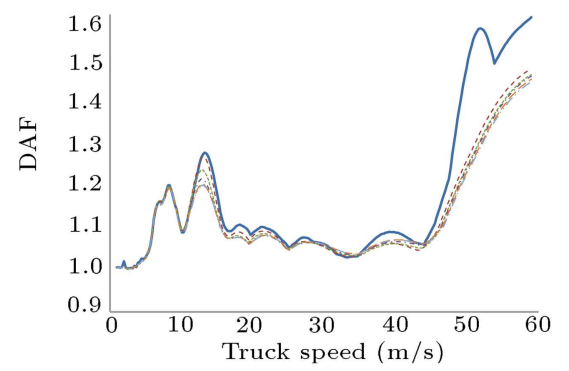

(d) $c=50 \mathrm{E} 6 \mathrm{Ns} / \mathrm{m}$

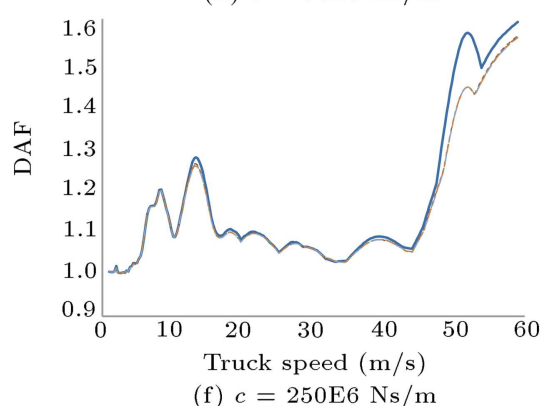

Figure 14. Influence of stiffness and damping of viscoelastic supports and truck speed on DAF of the 35 -m bridge with sinusoidal profile.

dynamic behavior of the bridges of case studies. The third row of Table 3 shows the observed amount of DAF reduction. It is obvious that these outcomes are not general and need more experimental research. Based on the investigated case studies, reduction in DAFs is about $4 \%$ to $5 \%$ in the cases of short and medium spans and no significant reduction is observed for long spans. In addition, using viscoelastic supports to reduce DAF is more efficient in the case of sinusoidal road profile and in the case of smooth road profile, no significant reduction is observed.

For emphasis, it must be mentioned that some of the presented comments in this section would not be true in general and need more tests and numerical or analytical research to be imported in future bridge codes.

\section{Conclusions}

In this paper, a model for simply supported and viscoelastic supported Euler-Bernoulli beams under moving trucks considering viscoelastic characteristic was presented. In this model, the governing equation of the beam, by using finite difference method, and the equation of motion of a moving truck, by using Wilson$\theta$ method as well as the trial and error method, were solved simultaneously. For simply hinged supports, good agreement was observed in the case of moving oscillator problem as well as damping effect on DAFs, which was analyzed by Cantero et al. [10]. Some test problems (different bridges with different spans, 4 cases; different road profiles, 2 cases; different truck speeds, 237 cases; and different viscoelastic supports characteristics, 31 cases; 58776 cases in total) for different bridges were solved by this algorithm. This approximate technique can be applied to beam structures and bridges with or without viscoelastic supports which are subjected to moving vehicle loading:

- This paper presents an algorithm to solve the governing equation of the bridge with or without 

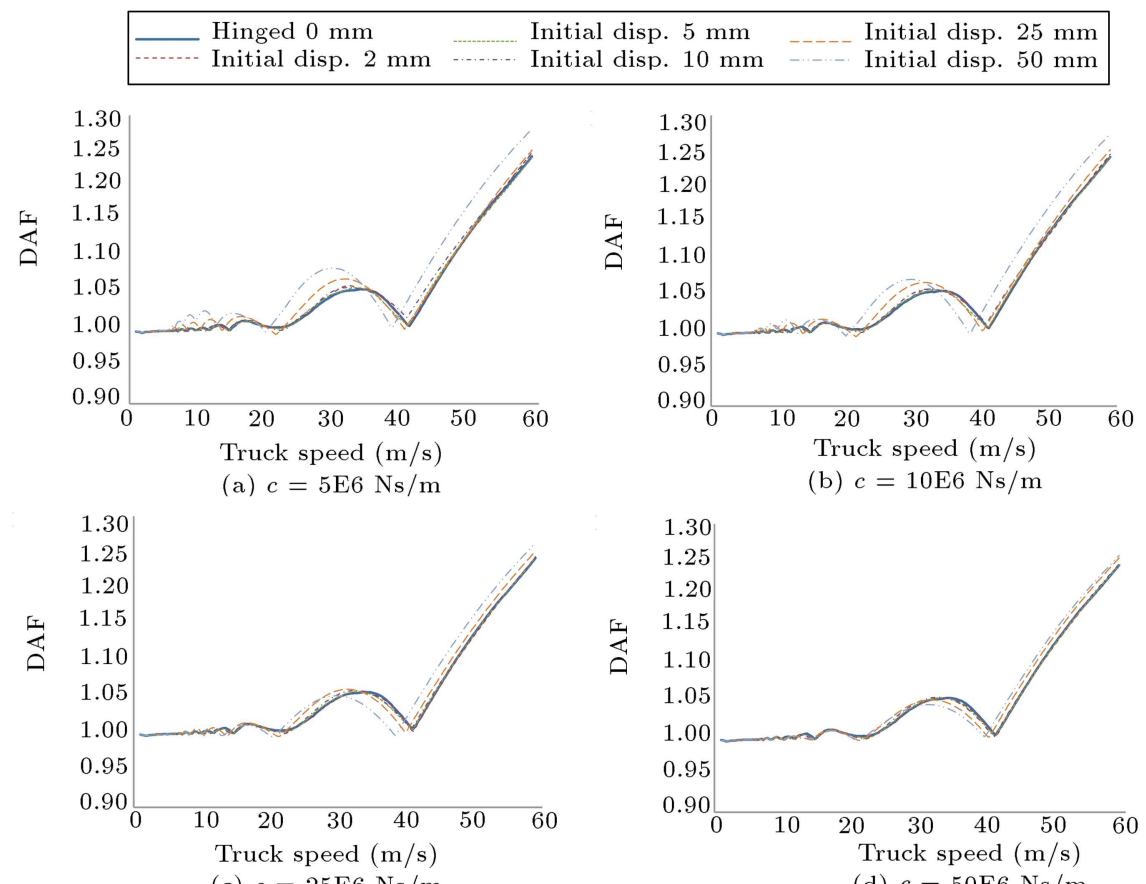

(b) $c=10 \mathrm{E} 6 \mathrm{Ns} / \mathrm{m}$
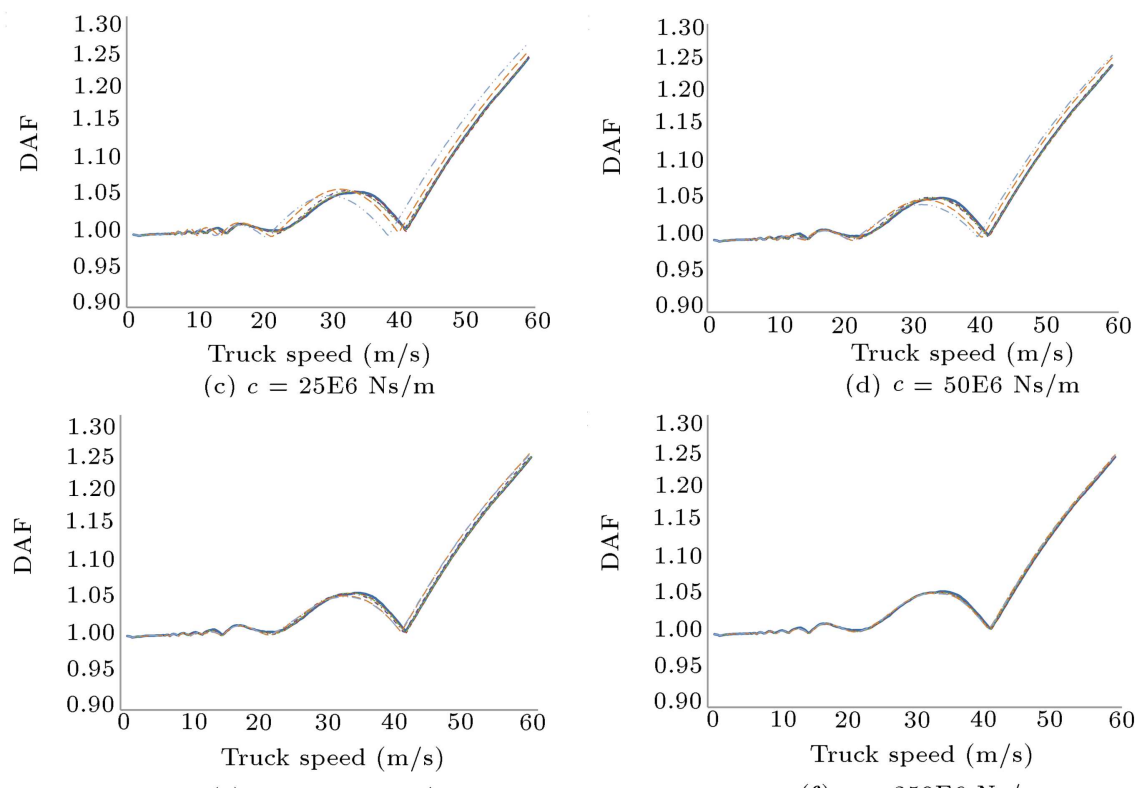

(d) $c=50 \mathrm{E} 6 \mathrm{Ns} / \mathrm{m}$

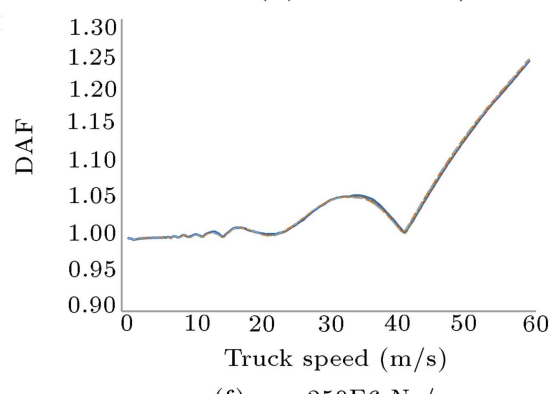

Figure 15. Influence of stiffness and damping of viscoelastic supports and truck speed on DAF of the 70-m bridge with smooth profile.

viscoelastic supports and the equation of motion of a real European truck with different speeds, simultaneously. Furthermore, the effect of viscoelastic supports on the maximum dynamic stress of bridges can make a tangible difference in magnitude;

- The existing bridge design codes, which have a conservative nature, are still adequate for designing highway bridges at normal traffic speeds. For instance, the AASHTO defines a factor called Dynamic Load Allowance (IM). The static effects of the design truck shall increase by 1.33 for dynamic load allowance. This approach is conservative at normal truck speeds on a smooth surface profile, but when trucks with higher speeds moving on an unsmooth road profile are considered, the problem becomes more complicated. Based on the investigated case studies, in this case, the dynamic load allowance or impact factor may increase up to 2.2 as illustrated in the article;

- Based on the investigated case studies, optimum amounts of damping and initial displacement on the viscoelastic supports, which lead to the highest DAF reduction, are proposed in Table 3 . It must be mentioned that these outcomes are not general and need more experimental research;

- Based on four different span case studies, which are described in Table 2, the moving European truck described in Table 1, and the use of viscoelastic supports, compared with simply hinged supports, it is seen that reduction in DAFs, for optimum damping and stiffness of viscoelastic supports, is about $5 \%$ in the cases of short and medium spans and no significant reduction is observed for long spans. Furthermore, the reduction in DAFs by using viscoelastic supports is tangible in the case of sinusoidal road profile and in the case of smooth road profile, no significant reduction is observed;

- Since dynamic amplification factor depends on several variables, resonance phenomenon can make significant differences in the magnitude of DAF 


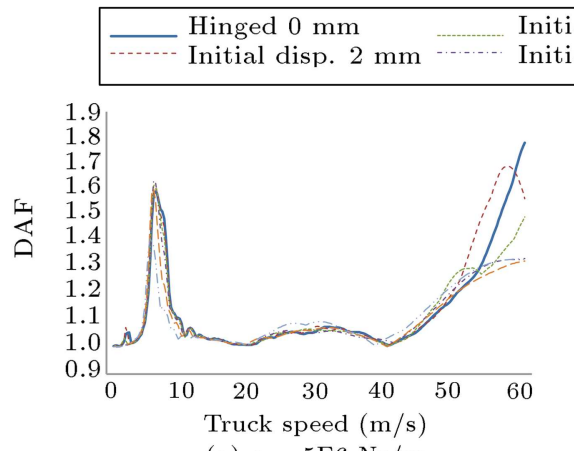

(a) $c=5 \mathrm{E} 6 \mathrm{Ns} / \mathrm{m}$

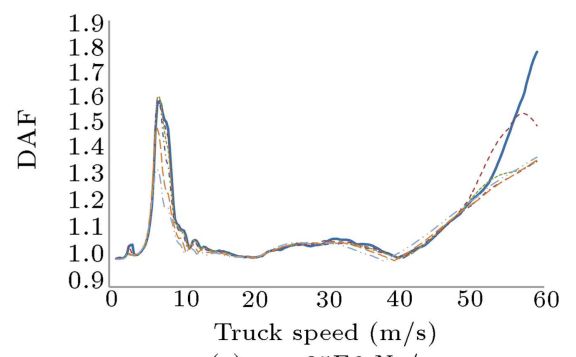

(c) $c=25 \mathrm{E} 6 \mathrm{Ns} / \mathrm{m}$

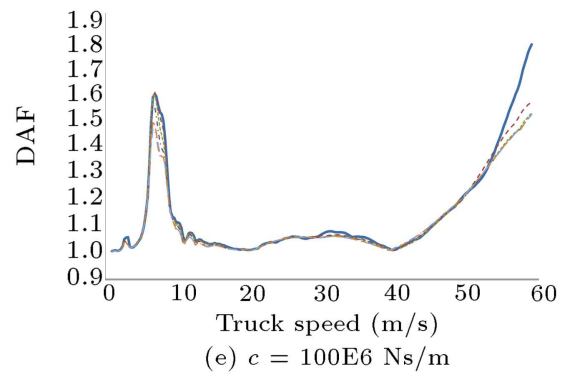

Initial disp. $25 \mathrm{~mm}$ Initial disp. $50 \mathrm{~mm}$

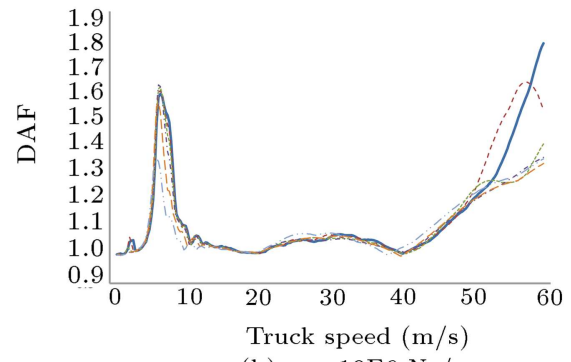

(b) $c=10 \mathrm{E} 6 \mathrm{Ns} / \mathrm{m}$

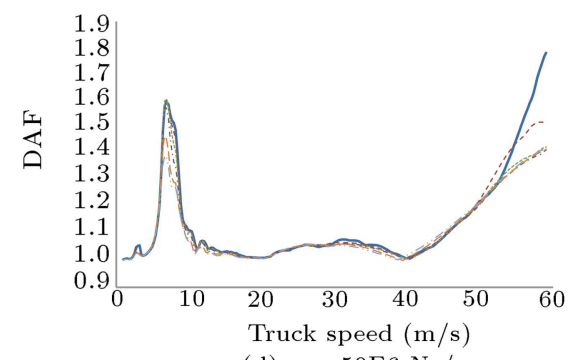

(d) $c=50 \mathrm{E} 6 \mathrm{Ns} / \mathrm{m}$

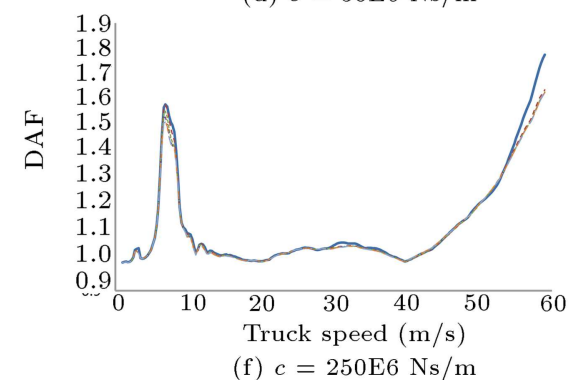

Figure 16. Influence of stiffness and damping of viscoelastic supports and truck speed on DAF of the 70-m bridge with sinusoidal profile.

at some local critical speeds. Using viscoelastic supports can decrease the local maximum DAFs in the case of short and medium spans up to $5 \%$;

- Regarding trucks and trains industry improvements and transportation developments as well as bridge modern instruments like viscoelastic supports, designing high-speed bridges will be needed in near future. Consequently, the new bridge and highway codes should make changes in their bodies based on new research correlated with experiments, either in situ or on lab models, particularly in calculating DAF of bridges on viscoelastic supports;

\section{References}

1. Akin, J.E. and Mofid, M. "Numerical solution for response of beams with moving mass", ASCE J. Struct. Eng., 115(1), pp. 120-130 (1989).

2. Fryba, L., Vibration of Solids and Structures Under Moving Loads, Noordhoff, Groningen, The Netherlands (1972).

3. Zheng, D.Y., Au, F.T. and Cheung, Y.K. "Vibration of vehicle on compressed rail on viscoelastic foundation",
ASCE Journal of Engineering Mechanics, 126(11), pp. 1141-1147 (2000).

4. Wang, Y.M. "The dynamical analysis of a finite inextensible beam with an attached accelerating mass", International Journal of Solids and Structures, 35 (910), pp. 831-854 (1998).

5. Siddiqui, S.A., Golnaraghi, M.F. and Heppler, G.R. "Dynamics of a flexible cantilever beam carrying a moving mass", Nonlinear Dynamics, 15(2), pp. 137154 (1998).

6. Siddiqui, S., Golnaraghi, M. and Heppler, G. "Large free vibrations of a beam carrying a moving mass", International Journal of Non-Linear Mechanics, 38(10), pp. 1481-1493 (2003).

7. Wang, Y.M. "The transient dynamics of multiple accelerating/decelerating masses traveling on an initially curved beam", Journal of Sound and Vibration, 286(12), pp. 207-228 (2005).

8. Dehestani, M. Mofid, M. and Vafai, A. "Investigation of critical influential speed for moving mass problems on beams", Applied Mathematical Modelling, 33(10), pp. 3885-3895 (2009).

9. Mofid, M. Tehranchi, A. and Ostadhossein, A. "On 
the viscoelastic beam subjected to moving mass", Advances in Engineering Software, 41(2), pp. 240-247 (2010).

10. Cantero, D. Gonzalez, A. OBrien, E.J. "Maximum dynamic stress on bridges traversed by moving loads", Bridge Engineering, 162(2), pp. 75-85 (2009).

11. American Association of State Highway and Transportation Officials, Standard Specification for Highway Bridges, SI Units 6th edition, Washington DC (2012).

12. O'Connor, C. and Shaw P.A., Bridge Loads. An International Perspective, Spon Press, London (2000).

13. British Standards Institution, Eurocode 1: Actions on Structures, Part 2: Traffic Loads on Bridges, BSI, London, BS EN 1991-2 (2003).

14. Gasic, V. Zrnic, N., Obradovic, A. and Bosnjak, S. "Considering of moving oscillator problem in dynamic responses of bridge cranes", FME Transactions, 39(1), pp. 17-24 (2011).

15. Zhang, Q., Jankowski, L., and Duan, Z. "Simultaneous identification of moving vehicles and bridge damage considering road rough surface", Mathematical Problems in Engineering, Article ID 963424 (2013).

16. Chang, K., Kim, C. and Kawatani, M. "Feasibility investigation for a bridge damage identification method through moving vehicle laboratory experiment", Structure and Infrastructure Engineering, 10(3), pp. 328345 (2014).

17. Samanipour, K., Vafai, H. "Effect of boundary conditions on dynamic behavior of bridges", Structures and
Buildings Proceedings of the ICE, 169(2), pp. 121-140 (2016).

18. Samanipour, K., Vafai, H. "Congestion effect on maximum dynamic stresses of bridges", Structural Engineering and Mechanics - An International Journal, 55(1), pp. 111-135 (2015).

\section{Biographies}

Kianoosh Samanipour graduated with BS degree in Civil Engineering and Mechanical Engineering (double major) from Sharif University of Technology, Tehran, Iran, in 2004. Afterwards, he graduated with MS and PhD degrees in Civil Engineering from Sharif University of Technology in 2006 and 2015, respectively. His research interests include seismic analysis of steel frames and dynamic load allowance factor on bridges.

Hassan Vafai, $\mathrm{PhD}$, is a Professor of Civil Engineering at Sharif University of Technology. He has authored/co-authored numerous papers in deferent fields of Engineering: Applied Mechanics, Biomechanics, Structural Engineering (steel, concrete, timber and offshore structures). He has also been active in the area of higher education and has delivered lectures and published papers on challenges of higher education, the future of science and technology and human resources development. 